\title{
TRANSFER EDİLEN RİTÜEL İLE TÜKETICİ TUTUMU VE SATIN ALMA DAVRANIŞLARI ARASINDAKİ İLIŞKİ: KARA CUMA ÖRNEĞİ
}

\author{
Aycan DURAN TEKOĞLU ${ }^{1,3}$ \\ Zeliha ESER ${ }^{2}$
}

\begin{abstract}
ÖZ
Bilginin ulus ötesi sınırlarda hızla yayılması, farklı kültürleri tanıma imkanının artması, küreselleşme ve göçler sonucunda ritüeller dönüşüm geçirmekte veya farklı coğrafyalara transfer edilerek o bölgelerde de uygulanmaktadır. Batı orijinli Kara Cuma da küresel pazarda firmaların pazarlama kampanyalarını şekillendirdiği tüketimle yakından ilişkili ritüellerden biri olarak dünyanın çeşitli bölgelerine transfer edilmektedir. Bu çalışma, Türkiye'deki tüketicilerin Batı'dan transfer edilen bir ritüele yönelik tutumları ve satın alma davranışlarını, tüketicilerin tutumlarıyla satın alma davranışı arasındaki çelişkiyi ve bu çelişkiye rağmen neden satın alma davranışında bulunduklarını incelemeyi amaçlamaktadır. Bu amaçla bilişsel uyumsuzluk kuramı ve tüketici sinizmi, tüketicilerin tutum ve satın alma davranışlarına yönelik açıklayıcı bir çerçeve olarak kullanılmıştır. Bu araştırmada, Kara Cuma ritüeli hakkında tüketicilerin çoğunlukla psikolojik, dini ve kültürel nedenlerle kapitalizme ve aşırı tüketime ilişkin düşüncelerden dolayı olumsuz tutum sergiledikleri görülmüştür. Ayrıca tüketicilerin tutumları ile satın alma davranışları arasında bir çelişki olduğu, tüketicilerin satın alma davranışlarını çeşitli gerekçelere dayandırarak rasyonelleştirmeye çalıştıkları sonucuna varılmıştır. Bunun yanı sıra, bazı tüketicilerin Kara Cuma'da dürtüsel satın alma davranışı gerçekleştirdiği sonucuna ulaşılmıştır.
\end{abstract}

Anahtar Kelimeler: Ritüel transferi, Kara Cuma ritüeli, tüketici tutumu, satın alma davranışı, bilişsel uyumsuzluk kuramı, sinizm

Doi: 10.15659/ppad.14.3.942924

Doktora öğrencisi, Başkent Üniversitesi, duran.aycan@gmail.com, ORCID: 0000-0002-7899-7766

Prof. Dr., Başkent Üniversitesi, zeser@baskent.edu.tr, ORCID: 0000-0002-1174-4238

İletişim Yazarı / Corresponding Author: duran.aycan@gmail.com

Geliş Tarihi / Received: 25.05.2021, Kabul Tarihi / Accepted: 12.09.2021 


\title{
THE RELATIONSHIP BETWEEN TRANSFERRED RITUAL WITH CONSUMER ATTITUDE AND PURCHASING BEHAVIORS: THE CASE OF BLACK FRIDAY
}

\begin{abstract}
Rituals are transformed or transferred to different geographies and applied in those regions due to the rapid spread of knowledge across transnational borders, increasing the possibility of getting to know different cultures, globalization, migration. Originated in the West, Black Friday is also transferred to various regions of the world as one of the rituals related to consumption that companies shape their marketing campaigns in the global market. This study aims to examine consumers' attitudes and buying behaviors towards a ritual transferred from the West in Turkey, the contradiction between the buying behavior and the attitudes of the consumers, and why they engage in buying behavior despite this contradiction. Therefore, cognitive dissonance theory and consumer cynicism were used as an explanatory framework for consumers' attitudes and buying behaviors. In this study, it was seen that consumers have negative attitudes about Black Friday, mostly due to psychological, religious and cultural reasons, as well as thoughts about capitalism and overconsumption. Additionally, it was concluded that there is a contradiction between the attitudes of the consumers and their buying behavior, and that consumers try to rationalize their behaviors by basing them on various reasons. Moreover, some consumers performed impulsive buying behavior on Black Friday.
\end{abstract}

Keywords: Ritual transfer, Black Friday ritual, consumer attitude, buying behavior, cognitive dissonance theory, cynicism 


\section{Giriş}

Birey, sosyal ve kültürel açıdan ilişkilerini, tutumunu ve davranışını etkileyen ritüellerle bir arada yaşamaktadır. Ritüeller doğumdan ölüme dek insan yaşamının tüm evrelerinde söz sahibi olmaktadır. Söz konusu ritüel davranışlar genellikle dramatik, törensel ve dinsel durumlarda tüketilen mal ve hizmet alışverişini içermektedir (Rook, 1985). Öyle ki tüketim, modern yaşamın temel ritüeli olarak bile yorumlanmaktadır (Wright ve Snow, 1980) çünkü ortalama bir insan her gün sayısız alışılmış davranış sistemine katılmaktadır (Browne, 1980).

Zaman içinde tekrarlanma eğilimindeki birden fazla davranıştan oluşan bir tür ifade edici, sembolik aktivite (Rook, 1985) olan ve küreselleşmenin etkisi ile dünya çapında kutlanan, kutsal veya kutsal olmayan ritüeller farklı coğrafyalardan transfer edilmektedir. Örneğin Noel, Hristiyan geleneği olmayan ülkelerde bile, dünya çapında her yıl kutlanan birkaç ritüelden biri haline gelmiştir (McKechnie ve Tynan, 2006). Gerek Batı kültürel emperyalizminin ve küresel homojenleşmenin kanıtı olarak gerekse melezleşme ve yerele ait olanların benimsenme biçimleri olarak, Batılı ritüellerin Batılı olmayan ülkelere yayılması ve dünyanın çeşitli yerlerinde yerel ritüellerin yeni formlarda yeniden canlanması önem kazanmaktadır (Sandıkçı ve Omeraki, 2007). Nitekim, Batı'dan Doğu'ya gerçekleşen ritüel transferi Doğu dünyasının kendi ritüellerini bir kenara bırakıp yalnızca transfer edilen ritüellerin uygulanmasına sebep olmamakta; yerleşik ritüeller ile transfer edilen ritüeller birlikte uygulanma eğilimi göstermektedir. Öyle ki artık yaşadığımız coğrafyada bir bebeğin doğmadan önce Batı'dan transfer edilen "Baby Shower" ritüeli ile gelişinin kutlandığı, aynı şekilde Cinsiyet Partisi ile cinsiyetinin öğrenilerek aile yakınları ile paylaşıldığı, doğumunun ise daha köklü ve İslam dinine özgü bir ritüel olan Bebek Mevlidi ile kutsandığ 1 görülebilmektedir. Bu ritüelleri Diş Buğdayı Partisi, Doğum Günü, Sevgililer Günü, Anneler Günü, Babalar Günü, Yılbaşı Kutlamaları, Kurban Bayramı ve Ramazan Bayramı gibi ritüeller takip etmektedir. Dolayısıyla ritüel transferi, karma ritüel uygulamasını beraberinde getirmektedir. Creighton'un (1993) Japonya'daki Sevgililer Günü'ne ilişkin çalışması transfer edilen bu ritüelin sadece nasıl benimsendiğini değil aynı zamanda nasıl adapte edildiğini de ortaya koymaktadır. Benzer şekilde düğün ritüelleri, küreselleşmenin etkisiyle yerel ve Batı tarzlarının karışımını içermektedir (Befu, 1984).

Diğer taraftan her ne kadar Batı'dan Doğu'ya gerçekleşen ritüel transferi Doğu'da yerleşik ritüellerle beraber uygulansa da ritüellerin ait olduğu kültüre derinden bağlı doğası sebebi ile Batı'dan transfer edilen ritüellerin benimsenmesi hiç de kolay olmamaktadır. Gregory, Munch ve Peterson (2002) kültürün, kişinin değer ve inançları, fikir ve tutumları ve iletişim yöntemleri olarak kullanılan semboller ve nesneler ile bağlantılı olduğunu belirtmektedir. Tarihsel bir olgu olan ritüel de kendini oluşturan toplumsal koşullardan, inanç sistemlerinden, kültürel yapıdan beslenmektedir. Öyle ki birey bir ürün satın alırken bile sahip olduğu değerlerden etkilenmektedir. Ürün, bireyin benimsediği değerleri ile sembolize ediliyor- 
sa bu ürüne karşı bireyin daha olumlu bir tutum sergileyeceği ve bu ürünü satın alma olasılığının artacağı ancak reddettiği bir değeri simgeleyen bir ürüne karşı ise bireyin olumsuz bir tutum sergileyeceği ve o ürünü satın alma olasıllğ̆ının daha düşük olacağı belirtilmektedir (Allen, Gupta ve Monnier, 2008). Örneğin Tayland, Hindistan, Kenya gibi ülkelerden Amerika'ya göç etmiş bireyler üzerine yapılan bir araştırmada bazı göçmen annelerin doğumdan önce hediye verdikleri veya aldıkları takdirde bebeğe bir şeyler olacağından endişe ettikleri ve bu sebeple "Baby Shower" ritüeline karşı oldukları; bazı göçmen annelerin ise bu ritüeli kendi kültürlerinde yer almasa dahi gerçekleştirdikleri görülmüştür (Wamwara-Mbugua, 2008). Bu bağlamda bireyin benimsediği değerler ile yakından ilişkili olan "ritüelin davranış üzerinde son derece güçlü bir etkisi" bulunmaktadır (Tetreault ve Kleine, 1990).

Markaların ve müşterilerin önemsediği bir indirim günü olarak yeni satış rekorlarlyla gündeme gelen Kara Cuma (Akcan, Gençyürek Erdoğan ve Karaçor, 2020; Kılıç, Budak ve Kılıç, 2020; Onbaş, 2020), 2012 yılından beri Türkiye'de Kasım ayının son cuma günü düzenlenen bir ritüel halini almıştır. İlk kez Amerika Birleşik Devletleri (ABD)'nde ortaya çıkan Kara Cuma Batı kültüründe tekrarlayan, sembolik ve kutsal rolleri ile bir ritüel olarak değerlendirilmektedir (Bell, Weathers, Hastings ve Peterson, 2014). Tüketici ilgisi açısından olumlu olması beklenen bir etkinliğe ilişkin olarak Türkiye'de özellikle sosyal medya üzerinden yoğun eleştirilerin yapıldığı görülmüş̧ür (Çetinkaya ve Ceng, 2018). Hatta Kara Cuma bazı tüketiciler tarafından İslami değerler ve kapitalizm bağlamında eleştirilmektedir (Dağtaş ve Yıldırım, 2018). Kara Cuma ritüelinde tüketim oranlarının yüksek olmasına karşın tüketicilerin olumsuz tutumları bir çelişki oluşturmaktadır. Bu bağlamda Batı'dan transfer edilen Kara Cuma ritüeline ilişkin tüketici tutumu ve satın alma davranışları arasındaki çelişkinin ve bu çelişkinin nedenlerinin araştırılmaya değer olduğu düşünülmektedir. Ayrıca araştırmacılar alışveriş ortamlarındaki kalabalıklaşmanın (Mattila ve Wirtz, 2008) ve ürünlerdeki indirimlerin (Dholakia, 2000) dürtüsel satın almaya yol açabileceğini saptamışlardır. $\mathrm{Bu}$ kapsamda tüketicilerin yoğun ilgi gösterdiği Kara Cuma ritüelinin plansız bir satın alma davranışı olan dürtüsel satın alma davranışına da neden olabileceği öngörülmektedir.

Çeşitli araştırmalarda, transfer edilen ritüel ve kültür ilişkisi (Langer, Lüddeckens, Radde ve Snoek, 2006; Langer, 2011; Werbner, 1986), ritüeller ile satın alma davranışı arasındaki ilişki (Kazançoğlu ve Aytekin, 2014; Ratcliffe, Baxter ve Martin, 2019; Rook, 1985; Sandıkçı ve Omeraki, 2007), tüketici sinizmi (Atılgan, İnce ve Y1lmaz, 2017; Bozoklu ve Ermeç, 2020; Güven, 2016; Özkaya ve Ülker, 2020; Tokgöz, 2020), tüketicinin "Kara Cuma" adlandırmasına yönelik sinik tutumu ve basına yansımaları (Akcan vd., 2020; Çetinkaya ve Ceng, 2018; Dağtaş ve Yıldırım, 2018; Yetmez, 2020), Kara Cuma'ya ilişkin kampanya analizleri (Onbaş, 2020), tüketicilerin Kara Cuma'ya ilişkin tutumları ve satın alma davranışları arasındaki çelişki (Şahin ve Yünaçtı, 2018) gibi farklı noktalara deği- 
nilmiştir. Literatür taraması kapsamında Batı'dan transfer edilen bir ritüele ilişkin satın alma davranışı gerçekleştiren tüketicilerin sinik tutumlarının nedenlerini, kültürle ilişkisini ve satın alma davranışlarının altında yatan gerekçelendirmeleri bilişsel uyumsuzluk kuramı çerçevesinde ele alan bir çalışmaya rastlanmamıştır. $\mathrm{Bu}$ çalışmada ritüelin kültür ile bağlantısı kurularak ve tüketicilerin transfer edilen bir ritüele ilişkin tutum ve satın alma davranışları ortaya konularak literatürde tespit edilen söz konusu açıkların kapatılması hedeflenmektedir. Aynı zamanda Batı dışındaki bağlamlarda gözlemlenen tüketim ritüeli çalışmaları, ritüellerin dinamizmini ve ritüeller ile modernite ve küreselleşmeye dayalı yapısal gelişmeler arasındaki ilişkiyi anlama konusunda daha fazla bilgi sağlamaktadır (Sandıkçı ve Omeraki, 2007). Bu nokta çalışmanın diğer bir motivasyon kaynağıdır.

Diğer taraftan araştırma bulgularının pazarlama stratejilerini oluşturmak adına uygulayıcılar için faydalı olacağı düşünülmektedir. Transfer edilen bir ritüel ile tüketicinin tutum ve davranışları arasındaki ilişkiyi ve tüketicinin etkilendiği yerel kültürün bu ilişkideki rolünü açıklayabilmek, ayrıca pazarlama uygulayıcıları için tüketicilere yönelik uygun stratejileri oluşturmak açısından konunun tüketici tutum ve davranışları, bilişsel uyumsuzluk ve tüketici sinizmi çerçevesinde ilgili kuram ve yaklaşımlarla ele alınmasının katkı göstereceği değerlendirilmektedir. Araştırmada bu amaçlar doğrultusunda aşağıdaki sorulara cevap aranmaktadır:

Araştırma Sorusu 1: Transfer edilen bir ritüele ilişkin tüketicilerin tutum ve satın alma davranışları arasındaki ilişki nasıldır?

Araştırma Sorusu 2: Yerel kültür, tüketicilerin transfer edilen ritüele ilişkin tutum ve davranışlarını nasıl şekillendirmektedir?

\section{Kavramsal Çerçeve}

\subsection{Ritüel ve Ritüelin Kültürle Bağlantısı}

Günlük yaşamda insanlar gerek bireysel gerekse grup olarak birtakım ritüellerin parçası olmaktadır. Rook (1985) ritüel terimini sabit, aralıklı bir sırada meydana gelen ve zaman içinde tekrarlanma eğiliminde olan birden fazla davranışın oluşturduğu bir tür ifade edici, sembolik aktivite olarak tanımlamaktadır. Tetreault ve Kleine (1990) ise ritüeli, amaçlı ve sosyal bağlamda standartlaşmış olan aktivite dizileri olarak ele almaktadırlar. Bununla birlikte bu yazarlar (1990), üyelerin ortaklaşa katılabileceği yoğun, çok sesli, belirsiz, duygusal ve bilişsel anlamlar ağını çağrıştırarak ve ileterek toplumsal karşılıklı bağımlılı̆̆ tekrar doğrulayan ritüelin hem sosyal hem de ahlaki düzeni korumak ve iletmek için tasarlanmış olduğundan bahsetmektedirler. Tanımlardan yola çıkarak ritüelin ortak bir geçmişe sahip olan bireyler arasında meydana gelen, toplumu doğrudan ilgilendiren, bir arada yaşamanın gereği olan sosyal ve ahlaki düzeni koruyan temalar olduğunu söylemek mümkündür. Bu bağlamda ritüelin kültürle ilişkili olduğu görülmektedir. Öyle ki Tetreault ve Kleine (1990), ritüel için sosyal olarak standartlaştırılmış kuralların hem açık hem de örtülü geleneksel gerekliliklerden oluştuğunu belirtmekte 
ve gizli kültürün bir parçası olarak örtük kuralların davranış üzerinde son derece güçlü bir etki yarattığını ifade etmektedirler.

Kültür "paylaşılan tutumlar, inançlar, kategoriler, öz tanımlar, normlar, rol tanımları ve değerler modeli" olarak tanımlanmıştır (Triandis, 1996). Kültürün göstergeleri olan değerler, kahramanlar, ritüeller ve semboller ise bireyin davranışını etkilemektedir (Hofstede, 1997). Bu bağlamda McCracken (1988), ritüelin bireylere kültürel düzenin geleneksel sembollerini ve anlamlarını doğrulama, anımsatma, belirleme veya gözden geçirme firsatı sunduğunu belirtmektedir. Örneğin, bireyin dini ritüellerine katılması o dinin üyeleri arasında duygusal bir bağ yaratmakta, dini sınırların içinde güveni teşvik etmekte ve dindarlığın birçok temel yönünü oluşturmaktadır (Mathras, Cohen, Mandel ve Mick, 2016). Dinin kültürün bir formu olduğu düşünüldüğünde (Cohen, 2009), ritüel kültürden bağımsız görülmemektedir. Kültürle şekillenen ritüel, ortak paylaşım sayesinde benimsenmekte ve sembolik aktivitelere dönüşmektedir. Bu kapsamda ritüelin belirli bir kültüre ait olmas1 o kültüre mensup bireylerin söz konusu ritüeli devam ettirmelerini de kolaylaştırmaktadır.

\subsection{Ritüelin Tüketim ile Bağlantısı}

Hayatımızın bir parçası haline gelmiş olan ritüellerin sıklıkla tüketimle bir arada gerçekleştiği görülmektedir. Örneğin, dini ritüellerden olan Ramazan Bayramı'nda, Kurban Bayramı'nda ve mevlitte gelen misafirlere yiyecek ikram edilmesi, dini kitapların misafirlere hediye edilmesi veya dini olmayan ritüellerden olan Sevgililer Günü’nde, Anneler Günü’nde, doğum günlerinde hediyeler verilmesi, çeşitli yiyecekler ile bu günlerin kutlanması ritüelin tüketimle yakından ilişkili olduğunu göstermektedir. Bu bağlamda ürünlerin bir ritüelin parçası olarak tüketilebildiği (Luna ve Gupta, 2001) görülmektedir. Günlük hayatımızda büyük bir yer kaplayan ritüeller tüketici davranışlarını da etkilemekte ve onları bilinçli veya bilinçsiz bir şekilde tüketime sevk etmektedir. Bu noktada Luna ve Gupta (2001), ritüellerin mal ve hizmet tüketimini içermesi sebebi ile tüketici davranış1 için önemli olduğundan bahsetmektedirler. Bununla birlikte aynı yazarlar, pazarlamacıların eylemlerinin, ritüele ilişkin davranışları biçimlendiren ve onların yayılmasına yardım eden reklamlar aracılığıyla ritüeller ile tüketici davranışı arasındaki karşılıklı ilişkiyi 1lımlı kıldığına değinmektedirler. Örneğin, reklamlarındaki belirli semboller ile Hallmark ve Kodak gibi firmalar bize özel bir anı kutlamak için bir kart göndermemiz veya film almamız gerektiğini hatırlatırlar (Otnes ve Scott, 1996). Zarantonello ve Luomala (2011) tarafından yapılan bir araştırmada tüketicilerin çikolata tüketimlerinin ritüelleri pekiştirdiği sonucuna varılmıştır. Araştırmada Paskalya'da çikolata vermenin ve almanın esas olarak uzun süredir devam eden gelenek ve ritüellerden kaynaklandığı belirtilmektedir. Bununla birlikte ritüeli pekiştirme aracı olan çikolata tüketim deneyimi, alışılmış davranışlar, kültürel adetler ve genellikle aile üyeleri ve arkadaşlarla paylaşılan değerli veya zorunlu deneyimlerin aracıları olarak hizmet eden ritüellerle ilişkilendirilmektedir (Fournier, 1991). Hatta çikolata, Sevgililer Günü ritüelinin de tarihsel dönüşü- 
münde Doğu ve Bat1, yerel ve küresel, tüketici ideolojisi ve pratiği arasında sembolik anlam transferi açısından merkezi ve uzlaştırıcı rol oynamaktadır (Minowa, Khomenko ve Belk, 2011). Bu kapsamda ritüellerin hem tüketim hem de pazarlama ile iç içe olduğu görülmektedir.

\subsection{Ritüel Transferi}

Ritüel transferi, bir ritüelin bir bağlamdan diğerine aktarılmasını veya -daha genel olarak- ritüeli çevreleyen bağlamın değişmesini ifade eder (Langer vd., 2006). Göç, ulus ötesi toplulukların ortaya çıkışı, küreselleşme, çoğulculuk, bilgi toplumu, dünya çapında entegrasyon veya temel kimliklerin (etnik köken veya din gibi) yeniden ortaya çıkması gibi koşullar altında ritüel transferi, ritüellerin gelişimine yeni bir bakış açısı sunmaktadır (Langer vd., 2006). Werbner (1986) çalışmasında ritüel transferinin, ritüelleri oluşturan metaforlar ve kültürel imgeleri durağan kabul eden "sınır işaretleme aracı" veya kültürel yer değiştirmenin sorunsuz olduğunu ve ritüelin yeniliğe yol açması gerekmediğini kabul eden bir "kopyalama" olarak görülmemesi gerektiğinden bahsetmektedir. Yazara göre ritüel canlı olup yeni deneyimlere tepki vermektedir. Bu bağlamda ritüel transferi, ritüelin tutarlı anlamsal yapısına şiddet uygulamadan veya sözdizimsel ilerleyişini baltalamadan gerçekleşir (Werbner, 1986). Sonuç olarak meydana gelen, ritüelin geçmiş ve şimdi arasında bağlantı kurarak yeni bir bağlama yerleşmesidir.

Geçmişten günümüze farklı toplumlar arasında gerçekleşen birçok ritüel transferi söz konusudur. Kültürle yakından ilişkili olan ritüelin farklı bir kültürde yer edinmesi ise kolay olmamaktadır. Transfer edilen ritüelin kimi zaman yerel kültüre adapte edildiği kimi zaman ise toplumda benimsenmediği görülmektedir. Örneğin, Minowa vd. (2011) tarafından yapılan araştırmada, Japonya' da Sevgililer Günü'nün kültürel olarak melezlenmiş bir tatil ritüeli olduğu ifade edilmektedir. Söz konusu araştırmada, Sevgililer Günü’nün Japon kültürel normlarına göre, kadınların erkeklere çikolata ve hediye verdiği ticari olarak inşa edilmiş bir tüketici tatili olarak benimsendiği anlaşılmaktadır. Bu kapsamda Batı'dan transfer edilmiş olan Sevgililer Günü’nün Japon kültürüne göre yeniden uyarlandığ1 sonucuna ulaşılmıştır. Ayrıca Sandıkçı ve Omeraki (2007) çalışmalarında dini bir ritüel olan Noel'in Japonya, Hindistan, Çin gibi Hristiyan nüfusun azınlıkta olduğu ülkelerde de kutlandığını, ancak bu ülkelerdeki Noel kutlama ritüelinin, Noel’i yerel kültüre dahil etmeye yardımcı olan hibritleştirilmiş veya melezleştirilmiş adaptasyonlar olduğunu belirtmektedirler. Bu bağlamda, transfer edilen ritüelin yeniden yorumlandığg görülmektedir.

\subsection{Bilişsel Uyumsuzluk Teorisi}

Bir birey birbiriyle ilgili ancak tutarsiz iki veya daha fazla bilgi unsuruna sahip olduğunda, bireyde oluşan rahatsızlık hali bilişsel uyumsuzluk olarak tanımlanmaktadır (Harmon-Jones ve Harmon-Jones, 2008). 
Festinger (1962) bilişsel uyumsuzluk kavramını bir örnek ile şöyle açılamaktadir:

"Eşiniz için eşit derecede çekici bulacă̆ından emin olduğunuz iki hediye alın. Her ikisini ... karınıza gösterin ve her birinin kendisine ne kadar çekici olduğunu söylemesini isteyin. Çekiciliğin iyi bir ölçümünü yaptıktan sonra, hangisini seçerse seçsin, onlardan birine sahip olabileceğini söyleyin. Diğerini mağazaya geri götüreceksiniz. Seçimini yaptıktan sonra, bir kez daha her birinin çekiciliğini değerlendirmesini isteyin. Seçimden önce ve sonra çekiciliğin değerlendirmelerini karşılaştırırsanız, muhtemelen seçilen hediyenin çekiciliğinin arttığını ve reddedilenin azaldığıın göreceksiniz."

Festinger (1962) bilişsel uyumsuzluk teorisinin, bir kişinin birbiriyle psikolojik olarak tutarlı olmayan şeyleri bildiğinde çeşitli şekillerde onları daha tutarlı hale getirmeye çalışacağı fikri etrafında odaklandığından bahsetmektedir. İnsanların duygu, düşünce ve davranışı arasında bir denge aradığ 1 , bu denge olmadığı zaman ortaya çıkan bilişsel çelişkinin kişiyi rahatsız ettiği ileri sürülmektedir (Festinger, 1957). Taylor, Peplau ve Sears'a (2006) göre uyumsuzluk, "tutumlarımızla tutarsız olan bazı davranışlarda bulunduğumuzda ortaya çıkan, itici güdüsel bir durum" olarak tanımlanmaktadır.

Bilişsel uyumsuzluk teorisine göre (Albarracin, Cohen ve Kumkale, 2003), ikna edici bir mesajın sonuçlarıyla çelişen bir davranışta bulunduklarının farkında olan kişilerin davranışlarını rasyonelleştirebilecekleri ileri sürülmektedir. Örneğin, bireyler daha önceki bir durumla çelişen davranışlarda bulunduklarında kaygı yaşayabilir ve uyumsuzluğu azaltmaya çalışabilirler. Bu durumda, çatışmaya maruz kaldıklarında çatışma yaşamadan önceki duruma kıyasla söz konusu davranışın daha olumlu özelliklere sahip olduğu sonucuna varabilirler (Albarracin vd., 2003). İnsanlar bilişsel uyumsuzluğu gidermek ve tutarsızlığı rasyonelleştirmek için tutumlarını değiştirebilirler yani seçtikleri seçeneğin önemini vurgularlar ve mevcut diğer alternatiflerin çekiciliğini görmezden gelmeye çalışırlar (Sharifi ve Esfidani, 2014). McGrath (2017) çalışmasında bilişsel uyumsuzluğu gidermek için bireylerin tutumlarını değiştirmelerinin yanı sıra farklı yöntemlere de başvurduklarını belirtmiş̧ir. Bireyler dikkatlerini uyumsuz bilişlerinden uzaklaştırarak, uyumsuzluğa neden olan olumsuz duygulanım durumundan kaçınarak veya uyumsuzluğu unutmaya bırakarak; bilişsel uyumsuzluğa yol açan davranışlarını önemsizleştirerek veya kendini onaylama ile tutarsız bir eylemin önemini zayıflatarak; davranışlarının sorumluluğunu reddederek; tutarsızlığa yol açan davranışı değiştirerek; inanç sistemine, davranışı ile uyumlu bilişler ekleyip tutarsız davranışı rasyonelleştirerek veya önceki ancak sorunlu bir davranışla tutarlı olan yeni bir eylem gerçekleştirerek bilişsel uyumsuzluğu giderebilir (McGrath, 2017). Örneğin, hamilelik sırasında sigara içmenin zararlı etkileri hakkında bilgi sahibi olunması ve sigaradan uzak durmaya yönelik sosyal baskıya maruz kalınmasına rağmen sigara içmek bilişsel bir uyumsuzluk yaratmaktadır. Goszczyńska, 
Knol-Michałowska ve Petrykowska (2016) tarafından yapılan çalışmada, sigara içen hamilelerin sigaranın zararlı olduğuna ilişkin bir bilince sahip olmalarına rağmen "sigara içmek belirli bir trimester döneminde zararsızdır, az sayıda sigara içmek fetüsün sağllğına tehlike oluşturmaz/az tehlikelidir." gibi öznel ifadelerle sigara içmelerine ilişkin destekleyici gerekçeler oluşturdukları ve bilişsel uyumsuzluğu gidermeye çalıştıklarından söz edilmiştir.

Sabit değer ve tutumlara ters düşen tercihler de bilişsel uyumsuzluğa yol açmaktadır (Odabaşı ve Barış, 2002'den aktaran Elüstün, 2020). Bu kapsamda, Türkiye'de Kara Cuma ritüeline ilişkin her ne kadar olumsuz tutum sergilense de satış rakamlarının yüksek olması tüketicilerin bilişsel uyumsuzluğa sahip olabileceklerini düşündürmektedir.

\subsection{Tüketici Sinizmi}

Sinizm, hem geniş hem de spesifik odaklı olabilen ve bilişsel, duyuşsal ve davranışsal bileşenlere sahip olan olumsuz bir tutum olarak tanımlanmaktadır (Stanley, Meyer ve Topolnytsky, 2005). Sinizm genellikle güvensizlik, şüphecilik, yetkililerin (satış personeli, firma, servis personeli gibi) yönlendirmelerine güvensizlik, memnuniyetsizlik, yabancılaşma ve yetkililere karşı direniş ve hatta düşmanlık tepkileri ile ilgilidir (Chylinski ve Chu, 2010). Örneğin, Burning Man gibi anti-tüketici festivallerinin de tüketici sinizminin bir sonucu olarak ortaya çıktığı söylenebilir.

Sinizm güçlü ve kritik bir psikolojik araç olarak görülmektedir. Öyle ki bu araç tüketicilerin, ikna etme girişiminin arkasındaki manipülasyonu görmelerini sağlamak ve tüketim toplumunun dayattığı tüketim kodunu deşifre etmek için "pazarlamanın gizli yönünün" (Cherrier ve Murray, 2004) ortaya çıkarılmasında yardımcı olmaktadır (Odou ve De Pechpeyrou, 2011). Tüketiciler hedefleri ve değerleri doğrultusunda değerlendirmelerde bulunmakta ve algılanan tutarsızlığa yanıt olarak bir dizi davranış benimsemektedir.

Tüketici sinizminin pazardaki davranışları ve algıları etkilediği, pazarı şekillendirdiği veya tüketici aktivizmine neden olduğu, eleştirel davranışları ve gönüllü sade yaşam tarzını benimseyerek pazardan çekilme davranışlarına yol açtığı gösterilmektedir (Helm, Moulard ve Richins, 2015).

Helm ve diğerlerine göre (2015) sinik tüketicilerin inançları üç kategoride sınıflandırılmaktadır:

1- Pazarda, kısa vadeli performansa aşırı vurgu ve üst yönetim ile çalışanları ve müşterileri arasındaki mesafe gibi 〈iyi〉 işletmelerin rekabet etmesini zorlaştıran sistemik hatalar vardır.

2- Yasal sistem ve devlet kurumları veya serbest piyasa gibi koruyucu sistemler etkin bir şekilde çalışmamaktadır. 
3- Tüketiciler, firmaları ödüllendirip cezalandırarak ve diğer tüketicileri etkileyerek daha büyük pazar sistemini şekillendirme sorumluluğuna sahiptir.

Çetinkaya ve Ceng (2018), Kara Cuma'ya ilişkin sosyal medya ortamında ifade edilen görüşlerle ilgili olarak tüketici sinizmi bağlamında duygusal bir analiz çalışması gerçekleştirmiştir. Söz konusu çalışmada, tüketicilerin genel olarak değerleriyle uyumsuz olduğu, güvenmedikleri ve şüphe duydukları için sosyal medya ortamında bu güne ilişkin görüşlerini olumsuz olarak dile getirdikleri sonucuna ulaşılmıştır. Chylinski ve Chu'ya (2010) göre de sinik davranışların sıklığ1 ve şiddeti, tüketicilerin hedefleri veya daha büyük ölçüde değerleri ile firma eylemleri arasında tekrarlanan uyumsuzluktan kaynaklanmaktadır. Bu bağlamda Batı'dan transfer edilen ve sosyal medyada olumsuz olarak nitelendirilen Kara Cuma ritüelinin Türk toplumunun değerleri ile uyuşmaması halinde, tüketicilerin Kara Cuma'da satın alma davranışında bulunmalarına rağmen bu güne ilişkin sinik tutuma sahip olabileceği öngörülmektedir.

\subsection{Ritüelin Satın Alma Davranıșı ile Bağlantısı}

Bireylerin veya kurumların ekonomik değeri olan ürün ve hizmetleri satın almalarını ve kullanmalarını kapsayan karar verme süreci satın alma davranışı olarak adlandırılmaktadır (Tek, 1999). Tüketici satın alma kararında kültürel değişkenlerin, sosyal değişkenlerin, kişisel değişkenlerin ve psikolojik değişkenlerin etkili olduğu ve söz konusu değişkenlerin birbiri ile yakın ilişkisinin bulunduğu görülmektedir (Eser, Korkmaz ve Öztürk, 2011). Bir ürünün satın alınmasında malların sahip olduğu ekonomik, teknolojik ve işlevsel faydalarının yanı sıra sembolik anlamlarının da etkili olduğu görülmektedir (Witt, 2010). Örneğin, Çinliler için hediye satın almak dostluğu ifade etmekte ve gelecek için iyi bir ilişki, bir gayretin başarılı bir sonucu, cömertlik veya yapılan bir iyilik için takdir umudunu sembolize etmektedir (Yau, Chan ve Lau, 1999).

Sembolik anlamlar taşıyan ritüellerin hem tüketim hem de pazarlama ile iç içe olduğu görülmektedir. Ritüeller yiyecek ve içecek tüketimi ile bağlantılıdır ve sosyal bağ, duygusal değişim ve artan tüketici algisı gibi psiko-sosyal faydalarla ilgilidir (Ratcliffe vd., 2019). Örneğin, doğum günü, Sevgililer Günü gibi ritüellerde hediye verilmesi destek ve samimiyetin birer sembolleri olarak değerlendirilmektedir (Blau, 1964).

Kwon ve Brinthaupt (2015), Kara Cuma'da alışveriş yapan tüketicilerin yapmayanlara kıyasla daha fazla hedonik alışveriş güdüsü sergiledikleri, indirimleri ve kampanyaları takip ettikleri, daha fazla para harcadıkları, alışveriş için daha fazla zaman sarf ettikleri ve daha fazla mağazayı ziyaret ettikleri sonucuna ulaşmışlardır. Bu kapsamda Kara Cuma ritüelinin tüketicilerin satın alma davranışı ile ilişkili olacağı öngörülmektedir. Özellikle hedonik motiflerin dürtüsel satın alma 
üzerinde olumlu bir etkiye sahip olduğu (Gültekin ve Özer, 2012) göz önünde bulundurulduğunda Kara Cuma ritüelinin dürtüsel satın alma davranışına da yol açabileceği düşünülmektedir.

\section{Araștırmanın Yöntemi}

\subsection{Bir Ritüel Transferi: Kara Cuma Örneği}

Kara Cuma, Şükran Günü’nden sonraki cuma günü, ABD'de perakende sektörü tarafından Noel tatili alışveriş sezonunun başladığını gösteren güne verilen isimdir. Şükran Günü, Kasım ayının dördüncü perşembe günü, Kara Cuma ise Şükran Günü'nden sonraki cuma günü kutlanmaktadır (Simpson, Taylor, O'Rourke ve Shaw, 2011). Kara Cuma teriminin ilk kez ne zaman ortaya çıktığı tam olarak bilinmese de kentsel bir mite göre ilk kez bu terimin 1965 y1lında Philadelphia şehir merkezindeki bir trafik polisi tarafından "Kara Cuma" günü meydana gelmiş trafiğe ve alışveriş yapan müşteri yoğunluğuna atıfta bulunmak için kullanıldığ belirtilmektedir (Apfelbaum, 1966). 1980'lere gelindiğinde, perakendeciler bu terimi tercih etmiş ve zararların kırmızı mürekkeple, kârların ise siyah mürekkeple kaydedildiği muhasebe uygulamalarını ifade etmek için kullanmışlardır (Simpson vd., 2011; Thomas ve Peters, 2011).

ABD'de yapılan bir araştırma kapsamında tüketicilerin Kara Cuma'yı tatil alışverişi ve özellikle de hediye ihtiyaçlarının giderilmesi açısından faydalı gördüğü ortaya çıkmıştır (Swilley ve Goldsmith, 2013). Bununla birlikte, Thomas ve Peters (2011) tarafından ABD'de yapılan bir başka araştırmada Kara Cuma alışverişlerinde tüketicilerin belirli stratejilerinin ve aşamalı planlarının bulunduğu da görülmektedir. İlk olarak alışveriş yapan kişi, yakınlarının yani ailesinin bu etkinlikte ona eşlik etmeleri için katılım göstermelerini sağlar (yani ailesel bağ). Grup daha sonra satışa sunulan en iyi ürünleri satın almak için en verimli yola dayalı ayrıntılı bir atak planı oluşturur (yani stratejik planlama). Üçüncü olarak grup indirimli ürünleri kapmak için mağazalara koşar (yani büyük yarış). Son olarak grup aynı şeyi yapmaya çalışan diğer tüm alışveriş yapanların pahasına indirimli ürünleri satın alarak başarıya ulaşır (yani görev tamamlandı). "Olayın ortak doğası (Kara Cuma alışverişi), önceden yapılan ayrıntılı planlama ve aktivitenin zamana bağlı doğası, Kara Cuma'y1, Şükran Günü, Cadılar Bayramı gibi geleneksel tatil ritüellerinden ödünç alınan ritüelin bir bölümü gibi göstermektedir... Bu nedenle Kara Cuma, geleneksel alışveriş ritüellerinin unsurlarını geleneksel tatil ritüellerinin unsurlarıyla harmanlayan, toplumsal yapısında benzersiz bir tüketim ritüelidir" (Thomas ve Peters, 2011). Araştırma kapsamında ayrıca Kara Cuma'nın hem tüketim hem de alışveriş ritüellerinde bulunmayan macera, rekabet ve aciliyet unsurlarına sahip olması nedeniyle tüketimle ilişkili bu ritüellerden farklı olduğu sonucuna varılmaktadır (Thomas ve Peters, 2011). Bell vd. (2014) tarafindan yapılan çalışmada da ABD'de önemli yıllık bir etkinlik olan Kara Cuma, Rook'un ritüel tanımında yer alan tekrarlayan, sembolik ve kutsal unsurları sağlaması ile bir ritüel olarak görülmektedir. 
ABD'de ortaya çıkmış bir ritüel olan Kara Cuma, Türkiye'ye de transfer edilerek Silk and Cashmere firması tarafından ilk kez 2012 yılında uygulanmaya başlanmıştır. Silk and Cashmere firmasının CEO'su Ayşen Zamanpur ile gerçekleştirilen ve 24 Kasım 2019 tarihinde Akşam gazetesinde yayınlanan röportajda Zamanpur, Kara Cuma'yı Türkiye'ye uygulama kararları ile ilgili şu ifadeleri kullanmıştır:

“Oğlum, Amerika'da okuduğu ylllarda 'Black Friday' indirimlerinden çok faydalanmış. Hem de okulda bu konuyu işlemişler. 2012'de Türkiye'ye dönüyordu. 'Neden biz de yapmıyoruz' gibi bir fikirle geldi. Ben bu fikre karşı çıktım, "Hem kara hem cuma bize hayatta uymaz" dedim. Ferhat, işe yeni girmiş ve CEO'yu ikna etmeye kararlı bir çalışan gibi çok ciddi bir dosya hazırladı. Ve bize son derece bilimsel bir sunum yaptı. Bu sunumda satış artış verilerinden, neden 'black' dendiğine kadar akla gelebilecek tüm soruların yanıtları vardı."

Zamanpur Kara Cuma ismi ile ilişkili görüşlerini ve satış kârını aşağıdaki ifadelerle dile getirmiştir:

“Amerika'da bir yıl Şükran Günü'nden sonraki cuma Şikago'da Noel alışverişi başladiğında o kadar yoğun bir trafik olmuş ki, insanlar saatlerce evlerine gidememiş. Ertesi gün bir gazete de 'Kapkara bir cumaydi' diye manşet atmış. Fakat ortaya çıkıyor ki o gün muhasebe hesaplarında bütün zarar rakamları pozitife dönmüş. Bir köşse yazarı 'kara cuma'lafinı kullanıyor ve o gün öyle anılmaya başlanıyor. Dini bir gönderme kesinlikle yok. Baktık 2-3 aylık satışlar da 2-3 gün içinde yapılıyor, ikna olduk ve 2012'de biz de bunu uygulamaya başladik.

Mağaza koordinatörüm sabah beni aradı ve 'Ayşen Hanım bunu görmeniz lazım'dedi, şoktaydı. İlk yll inanılmaz bir satış yaptık. İlk yıllarda bu kampanyada yalnızdık ama son 3 senedir herkes yapıyor."

Kara Cuma ismine yönelik görüşlerini dile getiren Zamanpur, bu isme ilişkin dini bir göndermenin bulunmadığından bahsetmektedir. Öte yandan Kara Cuma'nın dini bir açılımı olmadığından bahsedilmesi konunun dini bağlamda da ele alınmış olduğu izlenimini vermektedir. Öyle ki Kara Cuma ismine tepki olarak Diyanet İşleri Başkanlığı tarafından Aralık 2017'de hazırlanan “Güneşin Doğduğu En Hayırlı Gün: Cuma" isimli Cuma Hutbesinde şu ifadeler yer almaktadır (Güneşin Doğduğu En Hayırlı Gün: Cuma, 2017, parag. 7-8):

“...Son zamanlarda sikça duyduğumuz "Kara Cuma” ifadesi, müminler olarak hepimizi rahatsız etti. Zira bizim inancımızda bütün günler Allah'indır. Her günün sabahı, aydınlık bir geleceğe uyanıştır. Bir inancın sembolünü hedef alan ve mensupların yok sayan böylesi saygisiz ifade ve yaklaşımların bizim geleneğimizde yeri yoktur. Bir dinin kutsalının çılgınca ve sinırsızca bir tüketim anlayışına alet edilmesi asla kabul edilemez bir durumdur. 
Kardeşlerim! Zihinlerde olumsuz bir algı oluşmasına sebep olacak bu tür gayretler karşısında müminler olarak bizlere düssen, dinimize ve değerlerimize sımsıkı sarılmaktır. Bugün insanlığa karşı en önemli görevimiz, Yüce Dinimiz İslam'l, hidayet rehberimiz Kur'an'l, Alemlere Rahmet Peygamberimizi en iyi şekilde temsil etmektir, doğru tanitmaktır. Unutmayalım ki biz bu uğurda gayret ettiğimiz müddetçe Allah 'ın yardımı da bizimle beraber olacaktır."

Her ne kadar satış rakamlarının arttığı, tüketicilerin yoğun bir şekilde alışveriş yaptığı bir gün olsa da hutbede de belirtildiği üzere dini açıdan kutsallık atfedilen cuma günü için "kara" ifadesinin kullanılması tepkilere yol açmaktadır. Türkiye'de Kara Cuma ritüelinin İslami değerler bağlamında eleştirilmesinin yanı sıra bu ritüele ilişkin kapitalizm eleştirisinin de ön plana çıktığı görülmektedir (Dağtaş ve Yildirım, 2018).

\subsection{Araştırmanın Amacı ve Önemi}

Bu çalışmanın amacı Batı'dan transfer edilmiş ve tüketimi içinde yoğun şekilde barındıran bir ritüel olan Kara Cuma'ya ilişkin Türkiye'deki tüketici davranış1nı gözlemlemek, tüketicilerin tutumu ve satın alma davranışını değerlendirmek, tüketicilerin söylemleri ile davranışları arasındaki çelişkiyi bilişsel uyumsuzluk teorisine, tüketici sinizmine, kültür ve değerlerle ilişkisine göre ortaya koymaktır. Yapılan alanyazın taramasında Kara Cuma ritüelini bilişsel uyumsuzluk teorisi ve tüketici sinizmi bütününde ele alan bir çalışmaya rastlanılmamıştır. Bu nedenle çalışmanın akademik yazına katkı sağlayacağı düşünülmektedir.

\subsection{Araştırma Deseni}

Çalışma, tüketici tutumu ve satın alma davranışı arasındaki çelişkiyi anlamaya yönelik olup konuyu derinlemesine ve ayrıntılı bir şekilde araştırmayı amaçlamaktadır. Belli bir durum bağlamında deneyimin orijinal tanımında yer alan anlamlı somut ilişkilerin anlaşılması, fenomenolojik bilginin birincil hedefini oluşturmaktadır (Moustakas, 1994). Bu bakımdan fenomenolojik bir araştırma modeli üzerine çalışmanın temellendirilmiş olmasının bireylerin yaşadığı deneyimlerin ortak anlamının incelenmesine olanak sağlayacağı düşünülmektedir.

\section{4. Örneklem}

$\mathrm{Bu}$ çalışmada amaçlı örneklem yöntemlerinden biri olan ölçüt örnekleme yöntemiyle örneklem oluşturulmuştur. "Amaçlı örneklem, sayıdan ziyade, amaçlanan konuya bizi en iyi götürebilecek olan denek grup ve kişilerin seçimini esas almaktadır" (Sı ğrı, 2017). Ölçüt örneklem ise önceden belirlenmiş ölçütleri karş1layan durumları, gözden geçirmeyi ve incelemeyi içermektedir (Suri, 2011). Yıld1rım ve Şimşek (2008) söz konusu ölçütlerin araştırmacı tarafindan ya da önceden hazırlanmış bir ölçüt listesi aracılığıyla oluşturulabileceğini ifade etmektedirler. Kişisel bir gelire sahip olmak satın alma davranışını etkileyen önemli faktörlerden 
biri olarak görülmektedir (Qazzafi, 2020; Ramya ve Ali, 2016) Bu kapsamda, çalışmada Kara Cuma ritüeline ilişkin tüketici tutumu ve satın alma davranışı incelendiğinden Kara Cuma günü alışveriş yapmış ve düzenli geliri olan emekli veya çalışan bireyler tercih edilmiştir. Bununla birlikte tüketicilerin o günkü satın alma davranışını yakından gözlemlemiş olabileceklerinden ötürü mağaza ve kargo çalışanlarının görüşlerine de yer verilmiştir.

Katılımcılar, belirli konularda aynı şeyleri tekrarlamaya başlayana kadar ve edinilen her yeni bilgi bir öncekinden çok az yeni bilgi içerecek şekilde azalarak bir şey ifade etmeyene kadar (Thietart, 2001) yani satürasyon seviyesine ulaş1lana kadar mülakatlara devam edilmiştir.

Araştırma kapsamında 25 tüketici, 2 mağaza görevlisi ve 2 kargo şirketi çalışanı ile birebir görüşmeler gerçekleştirilmiştir.

\subsection{Veri Toplama Aracı ve Süreci}

Tüketicilerin görüşleri bilişsel uyumsuzluk teorisi, sinizm, satın alma davranışı ve tüketici tutumuna ilişkin literatüre dayanan yarı yapılandırılmış mülakat soruları çerçevesinde alınmıştır. Baş ve Akturan (2013) araştırmacının, araştırma amacını ve kendisini katılımcıya açıkça ifade etmesinin önemine değinmekte; aktif bir dinleyici olması gerektiğini vurgulamakta, mülakata genel konulardan ve sorulardan başlayarak daha sonra detay ve özel konulara değinmesinin faydalı olacağını belirtmektedir. Bu ilkeler çerçevesinde görüşmeler gerçekleştirilmiştir.

Araştırma, Ankara'da 27.11.2019 tarihinde Kara Cuma günü gerçekleştirilmiştir. Öncelikle alışveriş merkezine gidilerek mağazada ödeme yapmak üzere kasa s1rasında ve harcama yaptıkları için çekilişe katılmak üzere danışma sırasında bekleyen tüketiciler ile aynı gün internet üzerinden alışveriş yapmış olan tüketicilerle görüşmeler gerçekleştirilmiştir.

Aynı zamanda mağaza ve kargo şirketi görevlilerinin de görüşleri alınmıştır. Görüşmeler ortalama 5 ila 15 dakika arası sürmüştür. Görüşme sırasında katılımcıların izni dahilinde ses kaydı alınmış olup kayıtlar araştırmacılar tarafından deşifre edilmiştir.

\subsection{Güvenilirlik ve Geçerlilik}

Mülakat soruları alanında uzman iki akademisyene gösterilmiştir. Ardından soruların yeterince açık olup olmadığını test etmek amacıyla beş kişi ile pilot uygulama gerçekleştirilmiştir. Uzman ve pilot uygulama katılımcılarının görüşleri doğrultusunda mülakat sorularından bazıları çıkarılarak ve birleştirilerek gerekli düzenlemeler yapılmıștır. Mülakat soruları her bir katılımcıya aynı sıra ile sorulmuştur.

"Çalışmanın yapıldığ etmesine yardımcı olmaktadır” (Başkale, 2016). Bu bağlamda, verilerin topland1$\breve{g} 1$ alışveriş merkezine rutin ziyaretler gerçekleştirilmiş ve Kara Cuma günü mağa- 
zaların açılış saatinden kapanış saatine kadar mülakatın gerçekleştirildiği ortamda bulunulmuştur. Aynı gün internet üzerinden alışveriş yapmış olan tüketicilerle görüşmeler gerçekleştirilirken de yeterli vakit ayrılmıştır. Elde edilen sonuçların benzer ortam ya da gruplara aktarılabilirliğini sağlamak için amaçlı örnekleme yöntemi kullanılmış ve örneklem seçiminin nasıl yapıldığı belirtilmiştir (Başkale, 2016; Halıcı ve Çimen: 2021). Bununla birlikte, "güvenilirliğin sağlanması için farklı kaynaklar" (Yağar ve Dökme, 2018) olan tüketiciler, mağaza çalışanları, kargo görevlileri ile görüşmeler gerçekleştirilmiş ve "bulgularda katılımcıların demografik özelliklerine yer verilmiştir” (Baltac1, 2019). Ayrıca veri toplama araçlarının oluşturulması ve analiz edilmesi aşamalarında da uzman görüşüne başvurulmuştur.

Veri toplama sürecinin detaylı anlatımı ve ham verinin doğrudan alıntılar ile verilmesi araştırmanın geçerliliğini sağlamak için önemli görülmektedir (Creswell ve Miller, 2000). Bu bağlamda detaylı anlatıma yer verilmiş ve mülakatlar sırasında katılımcıların izni dahilinde ses kayıtları alınmış olup araştırmada katılımcıların görüşlerine doğrudan yer verilmiştir. Araştırmada, mülakat sorularına verilen cevaplarla ilgili literatür kapsamında oluşturulmuş olan tema ve kodların tutarlı olduğu görülmüştür. Bilişsel uyumsuzluk kuramı çerçevesinde bilişsel uyumsuzluğu giderici ifadelere, tüketici sinizmini dışa vuran ifadelere ve tüketici tutumunu yansitan ifadelere dayalı tema ve kodların mülakat sirasında katılımcı yanıtlarında karşı1ık bulduğu saptanmıştır. Ayrıca mülakat sırasında ve veri analizinde tarafsızlığın korunmasına dikkat edilmiştir.

\subsection{Veri Analizi Tekniği}

Araştırma kapsamında elde edilen veriler, nitel araştırmalarda kullanılan yazılımlardan biri olan QDA Miner programında analiz edilmiştir. Bu program, "verilerin bilgisayar ortamına aktarılması" ve "çeşitli kavramlar, kategoriler, cümleler, paragraflar vb. anlamsal ifadelerin bu program ile sayısal ifadelere dönüştürülmesi" prensibiyle çalışmaktadır (Sığrı, 2018). Katılımcıların yanıtlarından oluşan nitel veriler, QDA Miner programına yüklenmiş olup her bir katılımcının mülakat sorularına vermiş olduğu yanıtlar literatür kapsamında önceden oluşturulmuş olan kod listesi dikkate alınarak okunmuştur. Her bir ifadenin kod listesinde yer alan hangi kavramı karşıladığı keşfedilmeye çalışılmıştır. Ardından katılımcıların ifadelerinde yer alan paragraf, cümle veya sözcükler ile ilgili olan kodlar eşleştirilerek içerik analizine tabi tutulmuştur. Program aracılığıyla katılımcıların ifadelerinde söz konusu kodların ne kadar sıklıkla kullanıldığı ve literatürdeki teorik çerçevesi ortaya konulmuştur. Ayrıca katılımcıların ifadelerine doğrudan yer verilmiştir. Elde edilen veriler doğrultusunda çıkarımda bulunulmuştur.

\section{Bulgular}

\subsection{Katılımcıların Demografik Özellikleri}

Katılımcılara ilişkin bilgiler Tablo 1'de gösterilmektedir. Çalışmanın örneklemini oluşturan katılımcıların 17'sinin kadın, 12'sinin ise erkek olduğu görülmektedir. 
Araştırma kapsamında katılımcıların çoğunluğunun 21-30 ve 31-40 yaş aralığında olduğu tespit edilmiştir. Katılımcıların eğitim durumu incelendiğinde çoğunun lisans mezunu olduğu görülmektedir. Evli katılımcıların sayısının yüksek olduğu ve katılımcıların genellikle aylık 5.000 TL ila 10.000 TL aralığında gelire sahip oldukları saptanmıştır.

Tablo 1. Katılımcıların Demografik Özellikleri

\begin{tabular}{|ccc|}
\hline N =29 kişi & Kategori & $\mathbf{N}$ \\
Demografik & $21-30$ & 12 \\
& $31-40$ & 10 \\
Yaş & $41-50$ & 3 \\
& $51-60$ & 4 \\
\hline \multirow{2}{*}{ Cinsiyet } & Kadın & 17 \\
& Erkek & 12 \\
\hline \multirow{2}{*}{ Eğitim } & Lise & 7 \\
& Lisans & 17 \\
& Ön Lisans & 1 \\
\hline \multirow{2}{*}{ Medeni Durum } & Yüksek Lisans & 4 \\
\hline \multirow{2}{*}{ Gelir Durumu (Aylık/TL) } & Evli & 17 \\
& Bekar & 12 \\
\hline & $2500-5000$ & 10 \\
& $5001-10000$ & 16 \\
\hline
\end{tabular}

\subsection{Tüketicilerin Kara Cuma'ya İlișkin Tutumları ve Bilișsel Uyumsuzluk}

Tüketicilerin Kara Cuma'yı ve Kara Cuma ismini nasıl değerlendirdikleri yönünde görüşleri alınmış olup mülakatlarda belirttikleri ifadeler bilişsel uyumsuzluk teorisi, sinizm, Kara Cuma ritüeli, satın alma davranışı ve tüketici tutumuna ilişkin literatürdeki kavramlar çerçevesinde oluşturulan kodlarla ilişkilendirilmiştir. $\mathrm{Bu}$ kodlara ilişkin sıklıklar ise frekans analizi ile elde edilmiştir. Katılımcıların Kara Cuma'ya ilişkin olumsuz tutum nedenleri ve bilişsel uyumsuzluğu giderme ifadeleri Tablo 2'de gösterilmiştir. Tüketicilerin 16'sının Kara Cuma'ya ilişkin olumsuz tutum sergiledikleri görülmektedir. Ancak olumsuz tutum sergilemelerine rağmen Kara Cuma günü alışveriş yaptıkları gözlemlenmektedir. 
Tablo 2. Tüketicilerin Tutumları ve Bilişsel Uyumsuzluğu Giderme İfadeleri

\begin{tabular}{lll}
\hline Tüketiciler & Olumsuz Tutum Nedenleri & $\begin{array}{l}\text { Bilişsel Uyumsuzluğu } \\
\text { Giderme İfadeleri }\end{array}$ \\
\hline Katılımc1 3 & Kültürel ve Psikolojik & $\begin{array}{l}\text { Çocuklarım için } \\
\text { İhtiyaç }\end{array}$ \\
Katılımc1 4 & Dini ve Kültürel & Çocuklarım için \\
Katılımc1 5 & Kapitalizm ve Tüketime Teşvik & İhtiyaç \\
Katılımc1 6 & Psikolojik & İhtiyaç ve Çocuklarım için \\
Katılımc1 9 & Dini ve Psikolojik & İhtiyaç \\
Katılımc1 10 & Dini ve Kültürel & İhtiyaç \\
Katılımc1 11 & Dini & İndirim \\
Katılımc1 15 & Psikolojik, Kapitalizm ve Tüketime Teşvik & İndirim \\
Katılımc1 18 & Psikolojik & İndirim ve İhtiyaç \\
Katılımc1 19 & Psikolojik & İndirim \\
Katılımc1 20 & Kültürel, Kapitalizm ve Tüketime Teşvik & İhtiyaç \\
Katılımc1 21 & Dini ve Kültürel & İndirim \\
Katılımc1 22 & Kültürel ve Psikolojik & İndirim ve İhtiyaç \\
Katılımc1 23 & Kapitalizm ve Tüketime Teşvik & İndirim \\
Katılımc1 24 & Psikolojik, Kapitalizm ve Tüketime Teşvik & İndirim ve İhtiyaç \\
Katılımc1 25 & Dini, Kapitalizm ve Tüketime Teşvik & \\
\hline & &
\end{tabular}

Örneğin Katılımcı 9’un (Erkek, 46) bu ritüele dair görüşleri şöyledir:

"Ona çok karşlyım. Tamam ekonomik kriz diyorlar ama Amerika'da bir ekonomik kriz cuma günü olmuş. Ama bence alakası yok, tamamen İslamiyet karşıtı bir şey olduğunu düşünüyorum.”

Katılımc1 9'a neden Kara Cuma günü alışveriş yaptığ sorulduğunda ise aşağıdaki ifadelerle alışverişini gerekçelendirmiştir:

"İlk defa bu sene yaptılar çocuklarım. O da Kara Cuma olarak bahsedilmediği için ben aslında geldim. Muhteşem Cuma, biraz çevrildi ya. Ticari amaç güdüldüğ̈̈ için geldim, yoksa diğer türlü olsaydr yine hiçbir şey aldırmazdım. Açık söyleyeyim aldırmazdım yani. Yarın gelir alırdım, fazla para öderdim. Ama bugün yine aldırmazdım."

Diğer bir katılımcının bu güne dair düşüncesi ise şu doğrultudadır:

"Ben reddediyorum Cuma Müslümanların karası olamaz. Ben Kara Cuma'yı reddediyorum. Cumartesi yapsinlar. Pazar yapsinlar. Batı Müslümanları öldürüyor ama gavurların böceğini bile öldürmüyor. Ama benim psikolojimle oynamıyorlar ben oynattırmıyorum yani. Ben şu aldiğım ürünü ihtiyacımdan dolayı aldım” (Kat1lımc1 10, Erkek, 55). 
Bilişsel uyumsuzluk teorisine göre bilişsel uyumsuzluğun azaltılması, seçilen alternatifin çekiciliğini psikolojik olarak artırarak ve/veya reddedilen alternatifin çekiciliğini zihinsel olarak azaltarak, verilen kararın önemini bilişsel olarak geliştirerek, davranış değiştirerek (Schewe, 1973) ya da tutum-davranış ilişkisini daha mantıklı veya haklı gösteren bilişler ekleyerek (Simon, Greenberg ve Brehm, 1995) sağlanabilir. Bu kapsamda tüketicilerin Kara Cuma’ya ilişkin olumsuz tutumlarına rağmen gerçekleştirdikleri satın alma davranışlarını gerekçelendirmek amacıyla Kara Cuma'da alışveriş yapma sebeplerini birtakım gerekçelere dayandırmaya çalıştıkları görülmektedir. Söz konusu gerekçelerle tüketicilerin inanç sistemlerine, gerçekleştirdikleri davranışları ile uyumlu bilişler ekledikleri görülmektedir. Tablo 3'te olumsuz tutum ve bilişsel uyumsuzluğu giderme nedenlerine ilişkin kod listesinde de kullanılmış olan ifadelere ve bu ifadeleri kullanan tüketicilerin sayısına yer verilmiştir.

Tablo 3. Tüketicilerin Olumsuz Tutum Nedenleri ve Bilişsel Uyumsuzluğu Giderici İfadeleri

\begin{tabular}{|c|c|}
\hline Olumsuz Tutum Nedenleri & $\mathbf{N}$ \\
\hline 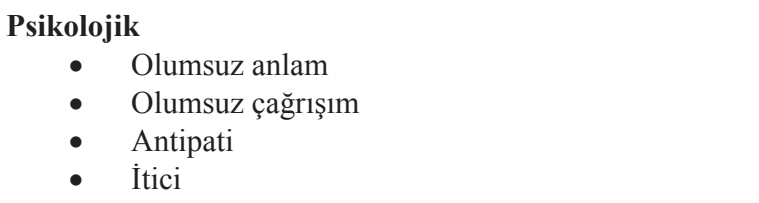 & 8 \\
\hline $\begin{aligned} \text { Dini } & \\
\text { - } & \text { Müslüman } \\
\text { - } & \text { İslam } \\
\text { - } & \text { Mübarek } \\
\text { - } & \text { Namaz } \\
\text { - } & \text { Muhafazakar }\end{aligned}$ & 6 \\
\hline $\begin{array}{cl}\text { Kültürel } & \\
\bullet & \text { Batı Kültürü } \\
\bullet & \text { Yurtdış1 }\end{array}$ & 6 \\
\hline $\begin{array}{c}\text { Kapitalizm ve Tüketime Teşvik } \\
\qquad \quad \text { Para harcamak } \\
\text { - } \quad \text { Kapitalizm } \\
\end{array}$ & 6 \\
\hline Bilişsel Uyumsuzluğu Giderme İfadeleri & $\mathbf{N}$ \\
\hline İhtiyaç & 9 \\
\hline İndirim & 8 \\
\hline Çocuklarım için & 3 \\
\hline
\end{tabular}

Olumsuz tutuma sahip olan tüketicilerin çoğunluğu kara sıfatının negatif bir anlama sahip olduğunu belirtmektedir. Bununla birlikte ölümü, üzüntüyü ve kötü günü çağrıştırdığını belirtmektedirler. Bu bağlamda psikolojik açıdan Kara Cuma ismine ilişkin olumsuz tutum sergilendiği görülmektedir. Müslümanlar tarafindan mübarek kabul edilen cuma gününün kara olarak nitelendirilmesinin de tüketiciler 
tarafindan olumsuz tutum sergilenmesine yol açtığı yapılan mülakatlar sonucunda elde edilmektedir. Ayrıca, Kara Cuma Batı kültürüne ait olarak görülmekte ve Türk kültürü ile bağdaştırılamamaktadır. Bu bağlamda kültürel açıdan da tüketicilerin olumsuz tutum içinde oldukları görülmektedir. Bununla birlikte, Kara Cuma "tüketim çılgınlı̆̆ı", "kapitalist sistemin bir parçası" gibi ifadelerle anılmaktadır. Tüketicilerin "kapitalizm” ve “tüketime teşvik” kavramları ile Kara Cuma’yı negatif anlamlandırdı̆̆ 1 görülmektedir.

\subsection{Kara Cuma'nın Tüketici Sinizmi ile Bağlantısı}

Tüketicilerin değerleri ile firma değerleri arasındaki uyumsuzluk tatminsizliğe ve zaman içerisinde tüketici sinizmine yol açmaktadır (Güven, 2016). Chylinski ve Chu, 2010 yılında yaptıkları araştırmada tüketici sinizmini duygusal, bilişsel ve davranışsal olmak üzere üç boyutta sınıflandırmışlardır. Araştırmalarında bilişsel boyutta güvensizlik ve şüphe; davranışsal boyutta direnç ve düşmanlık; duygusal boyutta ise yabancılaşma ve tatminsizlik kavramları ile ele alınmaktadır.

Katılımcıların 18'inin kullandıkları ifadeler kapsamında Kara Cuma'ya ve Kara Cuma’yı düzenleyen firmalara ilişkin güvensizliğe, düşmanca duygulara, tatminsizliğe ve aldatılma korkusuna sahip oldukları görülmektedir.

Katılımcı 13 (Kadın, 31) indirimlerin inandırıcı olmadığını ve bu indirimlere ilişkin şüphe duyduğunu belirtmektedir:

"Başlarda heyecanlandırıyordu indirimler beni. Kara Cuma'yı bekliyordum. Almak istediğim ürünleri indirimli alayım diye bekliyordum. Ama son dönemde işte indirimlerin gerçekçi olmadı̆̆gl, fiyatların önce artırılıp sonra yeniden düşürüldüğ̈̈ gibi yorumlar okuyunca, bu yönde bir şeyler görünce sosyal medyada paylaşımlar görünce bir parça soğudum. Indirimler, gerçekçiliği var mi yok mu diye şüphe uyandırdı bende."

Katılımcı 16 (Kadın, 23) da indirimlerin gerçekçi olmadığını ifade etmektedir:

"Kara Cuma'da biraz göstermelik indirimler yapıldığını düşünüyorum. Ama ona karşı da bir tutumum yok yani."

Katılımcı 22 (Kadın, 26) Kara Cuma’yı fırsatçılık olarak nitelendirmektedir:

"Yani bazı kalemlerde eğer takip edersen çok güzel indirimler olabiliyor Kara Cuma'da. Bunun peşine düşmek lazım. Ama bazılarını gerçekten sadece firsatçılık olarak görüyorum."

Katılımcı 23 (Kadın, 24) Kara Cuma’yı tatmin edici bulmadığını ifade etmektedir:

"Gereksiz. Ekonominin devam etmesi için olmasi gereken, gerektiği düşünülen ve bize böyle empoze edilen günler olarak düşünüyorum.", 
Katılımcı 10'un (Erkek, 55) Kara Cuma'ya ilişkin güvensiz bir tutum içinde olduğu görülmektedir:

"Kara Cuma ... hikaye. Kesinlikle hikaye. Şu fiyat geçen hafta da aynıydı bugün de aynı. Yarın da aynı olacak... Ben Kara Cuma'yı reddediyorum."

Araştırmada, Helm vd. (2015) tarafından geliştirilen üç alt boyuttan oluşan tüketici sinizmi ölçeğinde ve ilgili literatürde yer alan kavramlardan faydalanılarak oluşturulan kodlar ile mülakatlardaki ifadeler eşleştirilmiş ve sıklık analizi gerçekleştirilmiştir.

Tüketici sinizmine ilişkin en sık kullanılan kodlar Şekil 1'de gösterilmektedir.

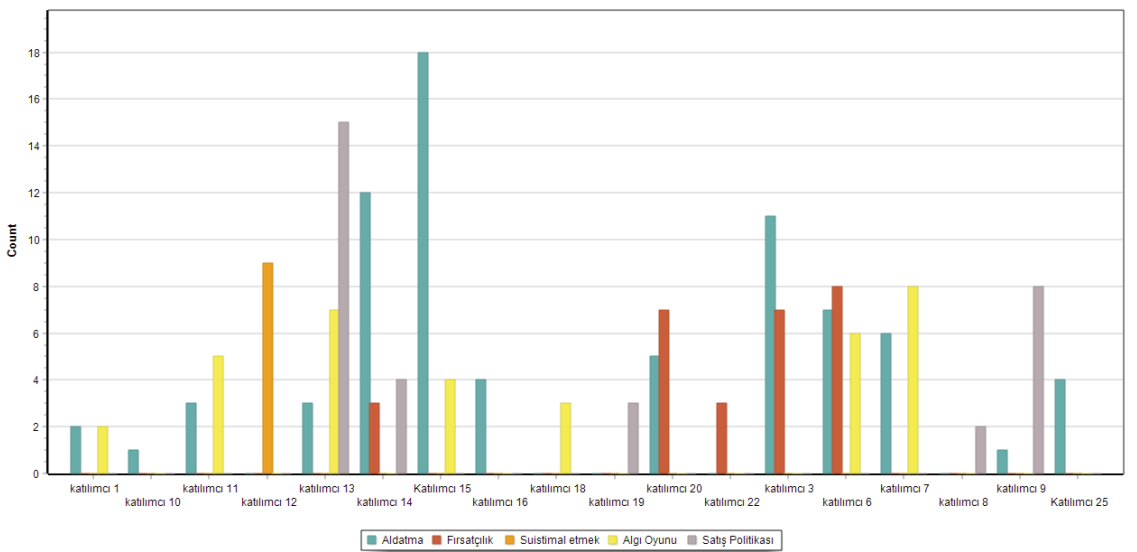

Şekil 1. Tüketici Sinizmine İlişkin Katılımcı Görüşleri

İndirimlerin gerçekçi olmaması aldatma kavramı içerisinde yer almakta olup firmaların tüketicileri düşünmeden sadece kendi çıkarları için hareket etmesi fırsatçılık kavramı ile açıklanmaktadır. Bununla birlikte tüketicilerin iyi niyetlerinin firmalar tarafından kötüye kullanılması suiistimal etmek kavramı ile bağdaştırılmaktadır. Tüketicilerin Kara Cuma'yı algı oyunu olarak nitelendirmeleri de bu kavramın sinizm başlığı altında değerlendirilmesini olanaklı kılmaktadır. Son olarak, Kara Cuma'nın firmaların tüketicileri piyasaya çekmek için düzenlenmiş bir satış politikası olarak görülmesi sebebi ile satış politikası kavramı da sinizm çerçevesinde ele alınmaktadır. $\mathrm{Bu}$ bağlamda, tüketicilerin Helm vd. (2015) tarafından geliştirilen sinizm ölçeğinde yer alan genel firsatçılık, doğrudan tüketicilere yönelik firsatçılık ve aldatma boyutları ile ilişkili ifadelerde bulundukları ve sinik tutuma sahip oldukları görülmektedir.

\subsection{Kara Cuma'ya İlişkin Kargo Çalışanı Görüşleri}

Kargo çalışanları ile gerçekleştirilen görüşmeler çerçevesinde Kargo Çalışanı 1 'in (Erkek, 30) görüşleri şöyledir:

"Çok fazla talep oldu. Biz de yetişmekte zorlandık. Teslimatlar da gecikti haliyle." 
Kargo Çalışanı 2 (Kadın, 29) ise Kara Cuma'ya dair deneyimlerini şöyle ifade etmektedir:

"Bu indirimlerden dolayı bir yoğunluk yaşadık. Kargoların bir günde teslim edilmedikleri oldu. Bu konularla ilgili çok sıkıntı yaşadık. Geldiği kadar da iade gitti. O kadar fazla oldu yani. Gecikmeler hem taleplerden hem de mesela Trendyol ekranı kapatt. Bir saatten sonra fatura kesimi olmadı. O yüzden de müşterilerin kargoları gecikti. Yani bir günde çıkacă̆ına iki gün sonra çıktı, diğger gün çıktı. Onlarda sıkıntı yaşadık."

Görüşmeler kapsamında gerek kargo şirketlerinde yaşanan yoğunluk sebebi ile gerekse satıcı firmaların tutumları sebebi ile tüketiciye ürünlerin ulaştırılmasında gecikmelerin yaşandığı görülmektedir. Bununla birlikte kargo şirketlerinde diğer günlere kıyasla daha fazla bir yoğunluğun yaşandığı anlaşılmaktadır. Powers ve Jack (2015) bir ürünle ilgili memnuniyetsizliğin duygusal bir uyumsuzluğa yol açacağını, bu uyumsuzluğun da ürün iadeleri ile pozitif ilişkili olduğunu bulmuşlardır. Kara Cuma günü iadelerin satın alınan ürünler kadar fazla olması, tüketicilerin dürtüsel satın alma yapmış olabileceklerini veya ürün iadelerini bilişsel uyumsuzluk kapsamında yaşanan pişmanlığı gidermek amacıyla gerçekleştirmiş olabileceklerini düşündürmektedir.

\subsection{Kara Cuma'ya İlişsin Mağaza Çalışanı Görüsşleri}

Mağaza görevlileri ile gerçekleştirilen görüşmeler çerçevesinde Mağaza Görevlisi 1 'in (Kadın, 27) görüşleri şöyledir:

"Sabah 9'dan itibaren buradaydım. Yani 10'da AVM kapanıor ama daha devam eder bu yoğunluk. İadeler çok oluyor."

Mağaza Görevlisi 2 (Kadın, 32) Kara Cuma günü çalışmanın fazla mesai gibi değerlendirildiğini belirtmektedir:

"Primimiz var. Kişisel olarak değil ama o saatte çalışıyorsan ve mă̆aza satışı yüksekse fazla mesai gibi düşünülüyor."

Mağaza çalışanlarının ifadelerinden Kara Cuma alışverişinde tüketici rağbetinin ve ürün iadelerinin fazla olduğu görülmektedir. Kara Cuma'da alışveriş yoğunluğunun diğer günlere nazaran daha fazla olduğu, bu günde alışveriş merkezlerinde çalışanlara prim verilmesi yoluyla motivasyon sağlanmasından da anlaşılmaktadır.

\subsection{Kara Cuma'nın Satın Alma Davranışı ile İlişsisi}

Görüşmeler kapsamında 25 tüketiciden 16'sının olumsuz tutuma sahip olmasına rağmen satın alma davranışı gerçekleştirdikleri görülmektedir.

Örneğin Katılımcı 4 (Erkek, 56) Kara Cuma’ya yönelik olumsuz tutuma sahip olmasına rağmen o gün satın alma davranışı gerçekleştirmiştir: 
"Cuma mübarek bir gündür. Cuma Müslümanın bayramı. Yurtdışında anladım ben Türk olmanın, Müslüman olmanın değerini. O kadar şanslıyız ki Türk olduğumuz için.. Bakma yani.. Kara Cuma olmaz kardeşim. Öyle bir şey mi olur? Müslümanız Elhamdulillah.

... Biz buraya geldik yani kuyumcuya geldik. Başka yerde bulamadık burada varmış buraya geldik. Sırf o yüzden alışveriş yaptık."

Katılımc1 18 (Erkek, 43), Kara Cuma’nın isim olarak kendisinde olumsuz bir anlam uyandırdığını belirtmesine rağmen satın alma davranışında bulunmuştur:

"İsim olarak bir garip geliyor da, yabancılardan alışık olduğum için böyle indirim olduğunu... Yoksa isim olarak Kara Cuma çok indirimi yansıtmıyor aslında. Iyi bir şeymiş gibi gelmiyor. Daha farklı bir isim bulunabilirdi. Kötü bir şeymiş gibi. İndirim gibi gelmiyor. Yani ters bir şey, o gün sanki alışveriş yapma der gibi. Olumsuz.

... O kadar çok reklam oldu ki yani beynime işledi herhalde. Televizyonda, Youtube'da... Inanılmaz etkilendim yani. Böyle normalde istediğim şeyler vard, hepsini bu vesileyle aldım."

Kara Cuma günü tüketicilerin 9'u (K5, K7, K8, K10, K13, K14, K15, K18 ve K24) ise akıllarında olmayan ürünleri de satın aldıklarını belirtmektedirler. Kararın genellikle mağazada o an verilmesinden dolayı bu tüketicilerin yaptıkları satın alma, dürtüsel satın alma olarak adlandırılmaktadır (Cobb ve Hoyer 1986) ve söz konusu satın alma davranışları ideal olan kararların karşısında görülmektedir (Chen ve Wang, 2016). Öyle ki bu katılımcılar arasındaki 5 kişinin (K5, K10, K15, K18, K24) aynı zamanda Kara Cuma’ya ilişkin olumsuz tutum sergilemesine rağmen satın alma davranışı gerçekleştirdikleri görülmektedir.

Katılımcı 15 (Kadın, 30) Kara Cuma'ya ilişkin olumsuz tutuma sahip oluğunu ancak aklında olmayan ürünleri o gün satın aldığını şu ifadelerle belirtmektedir:

"Kapitalist bir sistemin parçası olduğunu düşünüyorum. Kara Cuma eskiden köle ticaretinin yapıldı̆̆ günü ifade ediyormuş. Köle fiyatlarının düşürülerek satıldı̆̆ bir gün. Bu ismin buradan geldiğine yönelik herkesin bilgili olduğunu düşünmüyorum. Aslında olumsuz bir isim olarak değerlendiriyorum. Ayrıca kapitalizmin bir ürünü. Bazen yüksek fiyatlardaki ürünler indirilmiş olarak gösteriliyor. Ancak aslında fiyatlarda bir indirim olmuyor Aslında bir algı oyunu. Tüketicilere yönelik bir kandırma yapiliyor.

... Her sene alışveriş yapıyorum. Indirimden faydalanmak için alışveriş yapıyorum. Aslında genelde de çok alışveriş yapan biri olduğum için aldığım ürün miktarında değişiklik olmuyor... Evet aklımda olmayan şeyleri aldı̆̆ım oluyor." 
Katılımcıların, Kara Cuma'yı isim olarak olumsuz buldukları, İslam dini açısından uygun görmedikleri, kendi kültürleri açısından benimsemedikleri, kapitalizmle ve aşırı tüketimle ilişkilendirdikleri için olumsuz tutuma sahip oldukları görülmektedir.

\subsection{Kod ve Tema Listesi}

Helm vd. (2015) tarafından tüketici sinizmine ilişkin geliştirilen ölçekten, Festinger' in (1957) bilişsel uyumsuzluk teorisine ilişkin çalışmasından, olumlu ve olumsuz tutum ile dürtüsel satın almaya ilişkin literatürde bu kavramlar için yapılmış tanımlardan ve söz konusu teori ve kavramların yer aldığı geçmiş araştırmalardan yola çıkılarak kod ve tema listesi oluşturulmuştur. Mülakatlarda katılımcıların yoğun vurgu yaptığı ve literatürde yeri olan kavramlar da kod listesine eklenmiştir.

Helm vd. (2015) çalışmalarında, tüketici sinizmine ilişkin literatüre ve tüketicilerle yapılan görüşmelere dayalı bir ölçek geliştirmiştir. Tablo 4'te özetlenen tüketici sinizm ölçeği sekiz maddeden oluşmaktadır. Yapının ilk kavramsallaştırılmasına uygun olarak, revize edilmiş ve son hale getirilmiş ölçek sinizm kavramının üç unsurunun tümünü kapsar: genel firsatçılık (madde 4, 23, 32 ve 34), özellikle tüketicilere zarar veren firsatç1lik (madde $7,13,14$ ) ve aldatma (madde 18).

- Genel Fırsatçılık: Firmalar, temel ilkelere veya nihai sonuçlara bakılmaksızın kendi çıkarlarını gözetir.

- Doğrudan Tüketicilere Yönelik Firsatçılık: Firmalar kendi müşterileri için bile nihai sonuçları göz ardı ederek kendi çıarlarını gözetir.

- Aldatma: Aldatıcı pazarlama uygulamalarını özellikle vurgulayan firsatçılık uygulamalarıdır.

Tablo 4. Tüketici Sinikliği: Son Ölçek Maddeleri

4) Çoğu şirket yasaları çiğnemeyi önemsemez; para ve davaları sadece iş yapmanın bir maliyeti olarak görüyorlar.

7) Çoğu işletme, tüketicilere hizmet etmekten daha çok kar elde etmekle ilgilenir.

13) Şirketler tüketicileri manipüle edilecek kuklalar olarak görüyor.

14) Üreticiler ürünü satın aldıktan sonra ne olacağını umursamıyorlar.

18) Paramın karşılığını almak istersem, bir şirketin bana ne söylediğine inanmıyorum.

23) Çoğu şirket kâr elde etmek için her şeyi feda edecektir.

32) Kar elde etmek için şirketler ellerinden gelenin en iyisini yapmaya isteklidir.

34) Çoğu işletme kar marjlarını artırmak için ellerinden geleni yapacaktır.

Kaynak: Helm vd., 2015

Şekil 1'de yer alan tüketici sinizmine ilişkin katılımcı görüşlerinde, Helm vd. (2015) tarafından geliştirilen ölçeğe paralel olarak tüketicilerin aldatma, fırsatç1- 
lık, suiistimal etmek, alg1 oyunu ve satış politikası gibi genel fursatç1lık, doğrudan tüketicilere yönelik firsatçılık ve aldatma boyutları ile ilgili ifadelerde bulundukları görülmektedir. Bilişsel uyumsuzluk kuramı doğrultusunda tüketicilerin, satın alma davranışlarını daha tutarlı hale getirmek için ihtiyaçlarını, çocuklarının isteklerini ve indirimleri gerekçe olarak sundukları görülmektedir. Bununla birlikte akıllarında olmayan ürünleri aldıklarını ifade etmeleri dürtüsel satın alma davranışında bulunduklarına işaret etmektedir. Tüketiciler olumsuz tutumlarını ise Tablo 3 'te yer alan kodları kapsayan psikolojik, dini ve kültürel nedenler ile kapitalizm ve aşırı tüketimle ilişkilendirmişlerdir.

\section{Tartışma ve Sonuç}

Çalışmanın bulguları, transfer edilen Kara Cuma ritüeline ilişkin tüketicilerin sinik tutumlarını, bu tutuma rağmen gerçekleştirdikleri satın alma davranışlarının gerekçelerini ortaya koyması, tüketicilerin sahip olduğu değerler ile bağlantısını ele alması yönünden literatüre katkı sağlamaktadır.

Tüketicilerin büyük çoğunluğunun Kara Cuma ritüeli hakkında olumsuz tutuma sahip oldukları görülmüştür. Söz konusu olumsuz tutumun nedenleri başta psikolojik olmak üzere dini ve kültürel nedenler ile kapitalizme ve aşırı tüketime ilişkin düşüncelerden kaynaklanmaktadır. Schwartz'a (2009) göre kültürel değer vurguları birey ve grup inançlarını, eylemlerini ve hedeflerini şekillendirmektedir. Bu bakımdan çalışma kapsamında tüketicilerin ifadelerinde de sıklıkla kullandıkları kültürel değer vurgularının bireylerin tutumlarını şekillendirdiği sonucuna ulaşılmıştır. Öte yandan kültürel değer vurguları her ne kadar tüketicilerin tutumlarına yansımış olsa da bu vurguların satın alma davranışlarına yansımadığı görülmektedir. Kara Cuma'nın kendi kültürüne uygun olmadığını belirten tüketicilerin de o gün alışveriş yaptıkları görülmüştür. Chaharsoughi ve Yasory'nin (2012), kültürün değerler, kahramanlar, ritüeller ve sembollerle kendini gösterdiğini, değerlerin kültürün özünü oluşturduğunu ve tüketici davranışını etkilediğini belirtmelerine karşın bu araştırma çerçevesinde tüketicilerin vurguladıkları kültürel değerleri ile uyuşmayan bir satın alma davranışında bulundukları görülmüştür.

Ayrıca tüketicilerin kullandıkları ifadeler kapsamında Kara Cuma'ya ve Kara Cuma'yı düzenleyen firmalara ilişkin güvensizliğe ve aldatılma korkusuna sahip oldukları görülmektedir. Literatürde Kara Cuma ritüelinin tüketiciler tarafından dini değerler ve kapitalizm bağlamında eleştirilmesi (Dağtaş ve Yıldırım, 2018), ayrıca sosyal medya kullanıcılarının bu güne ilişkin olumsuz tutumlarının çoğunlukla değer uyumsuzluğu, şüphecilik-güvensizlik ve yıkıcılık-saldırganlık ile ilişkili olması çalışmanın bulguları ile paralellik göstermektedir.

Araştırmada olumsuz tutuma sahip olan tüketicilerin satın alma nedenlerine de yer verilmiş ve bilişsel uyumsuzluğu gidermek için tüketicilerin, davranışlarını aklamaya yönelik haklı yanlar aradıkları görülmüştür. Tüketicilerin büyük çoğunluğu Kara Cuma günü ihtiyaç ve indirim sebebi ile satın alma davranışında bu- 
lunduklarını ifade etmiştir. Goszczyńska vd. (2016) tarafından yapılan çalışmada, sigara içen hamile kadınların hamilelik döneminde sigarayı bırakmanın, gereksiz, imkansız, etkisiz ve hatta zararlı olduğunu sübjektif olarak rasyonalize ettiklerinden bahsedilmiştir. Benzer biçimde, araştırmamızda tüketicilerin Kara Cuma'ya ilişkin olumsuz tutumlarına rağmen satın alma davranışında bulunmaları ve bu davranışlarına ilişkin sübjektif gerekçeler sunmaları da bilişsel uyumsuzluk kuramı ile örtüşmektedir. Ayrıca bu sonuç, Şahin ve Yünaçtı'nın (2018) çalışmalarında ulaştıkları bulgular ile de uyumludur. Şahin ve Yünaçtı (2018) tarafından yapılmış olan çalışmada, tüketicilerin toplumun çoğunluğunun dini, kültürel, ideolojik, psikolojik nedenlerden dolayı Kara Cuma ritüeline ilişkin olumsuz tutuma sahip olduklarını belirttikleri ve kendilerinin de olumsuz tutum içinde oldukları ancak bu küresel ritüelde satın alma davranışı gösterdikleri ifade edilmiştir. $\mathrm{Bu}$ kapsamda transfer edilen bir ritüele ilişkin katılımcıların çoğunluğunun olumsuz tutuma sahip oldukları ancak bu tutuma rağmen satın alma davranışında bulundukları görülmüşsür.

Mağaza görevlileri ve kargo şirketi çalışanlarınca, Kara Cuma günü satın alınan malların ertesi günlerde iade edildiğinin belirtilmesi tüketicilerin bilişsel uyumsuzluklarını gidermek için (Powers ve Jack, 2015) böyle bir davranışta bulundukları sonucunu desteklemektedir.

Çavuşoğlu, Demirağ ve Durmaz (2020), Kara Cuma'da alışveriş merkezlerinin özellikle görsel, işitsel ve duyusal uyarıcılar ile mağazaların ambiyansını iyileştirdikleri, işletmelerin indirimli ürün satış stratejileri ile alışveriş merkezlerindeki cazip ortamın hedonik tüketimin bir unsuru olan plansız satın alma davranışını (dürtüsel satın alma) tetiklediği ve hedonik eğilimli tüketicileri daha fazla harcamaya ittiğini belirtmektedir. Al-Zyoud ve Amman (2019) çalışmalarında Kara Cuma ritüelinin dürtüsel satın alma davranışına yol açtığı sonucuna ulaşmışlardır. $\mathrm{Bu}$ çalışmada da Kara Cuma günü alışveriş yapan bir kısım tüketicinin dürtüsel satın alma davranışında bulunduğu sonucuna ulaşılmaktadır. Nitekim araştırma kapsamında tüketicilerin bir kısmı akıllarında olmayan ürünleri de satın aldıklarını ifade etmiştir.

Çalışmanın ulaştı̆̆ sonuçların pazarlama uygulayıcılarına da fayda sağlayacağı düşünülmektedir. Tüketicilerin bir ritüele ilişkin sahip olduğu olumsuz tutum, satın alma davranışı gerçekleştirmelerini engellemese dahi yaşadıkları bilişsel çelişki veya verdikleri anlık kararlar onları sonrasında almış oldukları ürünleri iade etmelerine yönlendirebilmektedir. Bu kapsamda bilişsel çelişkiyi ve anlık satın almanın verdiği pişmanlığı giderici pazarlama stratejilerinin firmaların kârlılı̆̆ını artırabileceği öngörülmektedir. Reklamlar ve promosyonlar yoluyla doğru bilgileri sunabilen şirketler, tüketicilerin marka sadakati geliştirmeleri konusunda şanslıdırlar (Fallon, 2012). Bu çalışmada elde edilen bulgular tüketicilerin firmaların yapmış olduğu indirime güven duymadıklarını ortaya koymaktadır. Firmaların tüketicilerin güvenlerini kazanmalarının marka sadakatini artıracağı değerlendirilmektedir. 
Batı'dan transfer edilen bir ritüel olarak Kara Cuma'nın ekonomik boyutunun yanı sıra toplumsal ve kültürel yönlerinin de dünyada ve Türkiye'de irdelenmeye başlandığı göze çarpmaktadır. Yerleşik kültürlere içkin ekonomik uygulamalarla birlikte transfer edilip hibrit formlar alan ritüeller, günümüzde oldukça etkin birer tüketim aracı olarak görülmeye başlanmıştır. Çalışmamızın konusu olan, Türkiye'deki tüketicilerin bu güne yönelik tutumları ve satın alma davranışları, tüketicilerin tutumlarıyla satın alma davranışı arasındaki çelişki ile bu çelişkiye rağmen satın alma davranışlarındaki gerekçelerine yönelik yapılan tespit ve açılamalar göstermektedir ki; Batı' dan transfer edilen Kara Cuma ritüeli hakkında tüketiciler çoğunlukla olumsuz tutum sergilemekte, Kara Cuma olgusu ve ismine yönelik negatif bir yaklaşımı paylaşmaktadırlar. Diğer taraftan, bu olumsuz tutum ve sinizm, onları alışveriş yapmaktan alıkoymamaktadır.

\section{Kısıtlar ve Gelecek Çalışmalara Öneriler}

Araştırma Ankara ilinde gerçekleştirilmiş olup farklı şehir ve ülkeleri kapsayan çalışmaların yapılmasının sonuçların genelleştirilmesine yardımcı olabileceği düşünülmektedir. Ayrıca, transfer edilen ritüel ile tüketici tutumu ve satın alma davranışları arasındaki ilişki bu çalışmada Kara Cuma ritüeli üzerinden gerçekleştirilmiş olup farklı örneklemlerde ve farklı ritüeller bağlamında yapılacak benzer çalışmaların ilgili literatüre katkı sunacağ düşünülmektedir. Bununla birlikte, tüketicilerin zaman içinde farklılaşan tutum ve davranışlarının gelecek çalışmalarda göz önüne alınması gerekmektedir.

Çalışmada, Kara Cuma ritüelinin dürtüsel satın alma davranışına da yol açtığı sonucuna ulaşılmıştır. Hedonik motiflerin dürtüsel satın alma üzerinde olumlu bir etkiye sahip olması sebebi ile gelecekteki çalışmalarda tüketicilerin sahip olduğu hedonik eğilimin göz önünde bulundurulmasının faydalı olacağı düşünülmektedir. Bilişsel uyumsuzluk teorisi kapsamında bir ritüel transferi olan Kara Cuma örneğinde tüketicilerin inanç sistemine, davranışı ile uyumlu bilişler ekleyip tutarsız davranış1 rasyonelleştirdikleri görülmüş ancak tüketicilerin davranış ve tutum değişikliği gibi diğer yöntemleri uygulayıp uygulamadıklarını görmek için gelecek çalışmalarda derinlemesine mülakatlar ve boylamsal bir araştırmanın yapılabileceği öngörülmektedir. 


\section{Kaynakça}

Akcan, B., Gençyürek Erdoğan, M. ve Karaçor, S. (2020). Para Cuma. Selçuk Üniversitesi Sosyal Bilimler Meslek Yüksekokulu Dergisi, 23(1): 43-53.

Albarracin, D., Cohen, J. B. ve Kumkale, G. T. (2003). When Communications Collide with Recipients' Actions: Effects of Post-Message Behavior on Intentions to Follow the Message Recommendation. Personality and Social Psychology Bulletin, 29(7): 834-845.

Allen, M. W., Gupta, R. ve Monnier, A. (2008). The Interactive Effect of Cultural Symbols and Human Values on Taste Evaluation. Journal of Consumer Research, 35(2): 294-308.

Al-Zyoud, M. F. ve Amman, A. (2019). How Black Friday Can Mess With Jordanian Customers' Minds. Academy of Strategic Management Journal, 18(4): $1-17$.

Apfelbaum, M. (1966). Philadelphia's Black Friday, American Philatelist, 69(4): 239.

Atılgan, K. Ö., İnce, T. ve Yılmaz, S. (2017). Tüketicilerin Satın Alma Niyetleri ve Boykota Yönelik Tutumlarının Tüketici Sinizmi, Fiyat Şeffaflığı ve Fiyat Adaleti Bağlamında İncelenmesi. ÇÜ Sosyal Bilimler Enstitüsü Dergisi, 26(3): 34-44.

Baltacı, A. (2019). Nitel Araştırma Süreci: Nitel Bir Araştırma Nasıl Yapılır?. Ahi Evran Üniversitesi Sosyal Bilimler Enstitüsü Dergisi, 5(2): 368-388.

Baş, T. ve Akturan, U. (2013). Nitel Araştırma Yöntemleri: NVIVO ile Nitel Veri Analizi, Örnekleme, Analiz, Yorum. 2. Baskı. Ankara: Seçkin Yayınevi.

Başkale, H. (2016). Nitel Araştırmalarda Geçerlik, Güvenirlik ve Örneklem Büyüklüğünün Belirlenmesi. Dokuz Eylül Üniversitesi Hemşirelik Fakültesi Elektronik Dergisi, 9(1): 23-28.

Befu, H. (1984). Civilization and Culture: Japan in Search of Identity. Senri Ethnological Studies, 16: 59-75.

Bell, G. C., Weathers, M. R., Hastings, S. O. ve Peterson, E. B. (2014). Investigating the Celebration of Black Friday as a Communication Ritual. Journal of Creative Communications, 9(3): 235-251.

Blau, P. (1964). Exchange and Power in Social Life. New York: Wiley.

Bozoklu, Ç. P. ve Ermeç, A. (2020). Tüketici Sinisizmi Ölçeği'nin Türkçe’ye Uyarlanması: Güvenilirlik ve Geçerlilik Araştırması. Ankara Hacı Bayram Veli Üniversitesi İktisadi ve İdari Bilimler Fakültesi Dergisi, 22(2): 440-459.

Browne, Ray B. (1980). Rituals and Ceremonies in Popular Culture, ed. Ray B. Browne, Bowling Green, OH: Bowling Green University Popular Press. 
Chaharsoughi, S. A. ve Yasory, T. H. (2012). Effect of Sales Promotion on Consumer Behavior Based on Culture. African Journal of Business Management, 6(1): 98-102.

Chen, Y. F. ve Wang, R. Y. (2016). Are Humans Rational? Exploring Factors Influencing Impulse Buying Intention and Continuous Impulse Buying Intention. Journal of Consumer Behaviour, 15(2): 186-197.

Cherrier, H. ve Murray, J. B. (2004). The Sociology of Consumption: The Hidden Facet of Marketing. Journal of Marketing Management, 20(5-6): 509-525.

Chylinski, M. ve Chu, A. (2010). Consumer Cynicism: Antecedents and Consequences. European Journal of Marketing, 44(6): 796-837.

Cobb, C. J. ve Hoyer, W.D. (1986). Planned Versus Impulse Behavior. Journal of Retailing, 62: 67-81.

Cohen, A. B. (2009). Many Forms of Culture. American Psychologist, 64: 194204.

Creighton, M. R. (1993). 'Sweet Love' and Women's Place: Valentine's Day, Japan Style. Journal of Popular Culture, 27 (3): 1-19.

Creswell, J. W. ve Miller, D. L. (2000). Determining Validity in Qualitative Inquiry. Theory into Practice, 39(3): 124-130.

Çavuşoğlu, S., Demirağ, B. ve Durmaz, Y. (2020). Investigation of the Effect of Hedonic Shopping Value on Discounted Product Purchasing. Review of International Business and Strategy.

Çetinkaya, O. A. ve Ceng, E. (2018). Türkiye'deki Black Friday Etkinliğinin Tüketici Sinizmi Bağlamında Bir Değerlendirmesi. MANAS Sosyal Araştırmalar Dergisi, 7(4).

Dağtaş, E. ve Yıldırım, O. (2018). Kültürel Emperyalizm Çerçevesinde Tüketim Pratiklerinin Türkiye Basınındaki Yansımalarının Çözümlenmesi: 24 Kasım 2017 "Kara Cuma” Örneği. Global Media Journal: Turkish Edition, 9(17).

Dholakia, U. M. (2000). Temptation and Resistance: An Integrated Model of Consumption Impulse Formation and Enactment. Psychology \& Marketing, 17(11): 955-982.

Elüstün, O. (2020). Tüketici Davranışlarında Bilişsel Uyumsuzluk. Economics Business and Organization Research, 2(1): 37-51.

Eser, Z., Korkmaz, S. ve Öztürk, S. A. (2011). Pazarlama, 2. Bask1, Ankara, Siyasal Kitapevi.

Fallon, M. (2012). "Like" to Loyalty: A Study on Whether or not Social Media Promotions Lead to a Lifetime of Consumer Brand Loyalty. UW-L Journal of Undergraduate Research, 15. 
Festinger, L. (1957). A Theory of Cognitive Dissonance, Stanford University Press

Festinger, L. (1962). Cognitive Dissonance. Scientific American, 207(4): 93-106.

Fournier, S. (1991). Meaning-Based Framework for the Study of Consumer-Object Relations. Advances in Consumer Research, 18: 736-42.

Goszczyńska, E., Knol-Michałowska, K. ve Petrykowska, A. (2016). How Do Pregnant Women Justify Smoking? A Qualitative Study with Implications for Nurses' and Midwives' Anti-tobacco Interventions. Journal of Advanced Nursing, 72(7): 1567-1578.

Gregory, G. D., Munch, J. M. ve Peterson, M. (2002). Attitude Functions in Consumer Research: Comparing Value-Attitude Relations in Individualist and Collectivist Cultures. Journal of Business Research, 55(11): 933-942.

Gültekin, B. ve Özer, L. (2012). The Influence of Hedonic Motives and Browsing on Impulse Buying. Journal of Economics and Behavioral Studies, 4(3): 180189.

Güven, E. (2016). Tüketimde Sinik Tutum: Tüketici Sinizminin Sebep ve Sonuçları. İşletme Araştırmaları Dergisi, 8(2), 152-174.

Halıcı, A. ve Çimen, Z. (2021). Futbol Seyircilerinin Etkinlik Kalitesine Yönelik Beklentilerinin Değerlendirilmesi. Pazarlama ve Pazarlama Araştırmaları Dergisi, 14(2): 389-421.

Harmon-Jones, E. ve Harmon-Jones, C. (2008). Action-Based Model of Dissonance: A Review of Behavioral, Anterior Cingulate, and Prefrontal Cortical Mechanisms. Social and Personality Psychology Compass, 2(3): 1518-1538.

Helm, A. E., Moulard, J. G. ve Richins, M. (2015). Consumer Cynicism: Developing a Scale to Measure Underlying Attitudes Influencing Marketplace Shaping and Withdrawal Behaviours. International Journal of Consumer Studies, 39(5): 515-524.

Hofstede, G. (1997). Cultures and Organizations: Software of the Mind, McGraw-Hill, New York, NY.

“Kara Cuma” Silk and Cashmere'e yaradı. (2015, 30 Kasım). Erişim adresi: https:// www.perakende.org/kara-cuma-silk-and-cashmeree-yaradi-1342802189h. html

Kazançoğlu, İ. ve Aytekin, P. (2014). Sevgililer Günü Ritüellerinin Alışveriş Deneyimi ve Hazcı Alışveriş Değerine Etkisi: Alışveriş Merkezlerinde Bir Uygulama. Uluslararası Yönetim İktisat ve Isşletme Dergisi, 10(22): 67-93.

Kılıç, G., Budak, İ. ve Kılıç, B. S. (2020). Kara Cuma Etiketlerinin Tweet İstatistikleri ve Duygu Analizi ile Sıralanması. Selçuk Üniversitesi Sosyal Bilimler Meslek Yüksekokulu Dergisi, 23(1): 131-140. 
Kwon, H. J. ve Brinthaupt, T. M. (2015). The Motives, Characteristics and Experiences of US Black Friday Shoppers. Journal of Global Fashion Marketing, 6(4): 292-302.

Langer, R., Lüddeckens, D., Radde, K. ve Snoek, J. (2006). Transfer of Ritual. Journal of Ritual Studies, 20(1): 1-10.

Langer, R. (2011). Transfer Processes within Sufi Rituals: An Example from Istanbul. European Journal of Turkish Studies. Social Sciences on Contemporary Turkey, (13).

Luna, D. ve Gupta, S. F. (2001). An Integrative Framework for Cross-Cultural Consumer Behavior. International Marketing Review, 18(1): 45-69.

Mattila, A. S. ve Wirtz, J. (2008). The Role of Store Environmental Stimulation and Social Factors on Impulse Purchasing. Journal of Services Marketing, (22): 562-567.

Mathras, D., Cohen, A. B., Mandel, N. ve Mick, D. G. (2016). The Effects of Religion on Consumer Behavior: A Conceptual Framework and Research Agenda. Journal of Consumer Psychology, 26(2): 298-311.

McCracken, G. (1988). Culture and Consumption: New Approaches to the Symbolic Character of Consumer Goods and Activities, Indiana University Press, Bloomington, IN.

McGrath, A. (2017). Dealing with Dissonance: A Review of Cognitive Dissonance Reduction. Social and Personality Psychology Compass, 11(12).

McKechnie, S. ve Tynan, C. (2006). Social Meanings in Christmas Consumption: An Exploratory Study of UK Celebrants' Consumption Rituals. Journal of Consumer Behaviour: An International Research Review, 5(2): 130-144.

Minowa, Y., Khomenko, O. ve Belk, R. W. (2011). Social Change and Gendered Gift-Giving Rituals: A Historical Analysis of Valentine's Day in Japan. Journal of Macromarketing, 31(1): 44-56.

Moustakas, C. (1994). Phenomenological Research Methods. Thousand Oaks, CA: Sage.

Odou, P. ve De Pechpeyrou, P. (2011). Consumer Cynicism: From Resistance to Anti-Consumption in a Disenchanted World?. European Journal of Marketing, 45(11/12): 1799-1808.

Onbaş, K. (2020). Sosyal Medyada Black Friday Reklamlarının Görünürlüğü Üzerine Bir Analiz: Hepsiburada ve Trendyol Örnekleri. Journal of Humanities and Tourism Research, 10(3): 568-586.

Otnes, C. ve Scott, L. M. (1996). Something Old, Something New: Exploring the Interaction Between Ritual and Advertising. Journal of Advertising, 25(1): $33-50$. 
Özkaya, B. ve Ülker, Y. (2020). Markaların Sosyal Medyada Oluşan Sinik Tutuma Yönelik Yaklaşımları. MANAS Sosyal Araştırmalar Dergisi, 9(1): 115-128.

Powers, T. L. ve Jack, E. P. (2015). Understanding the Causes of Retail Product Returns. International Journal of Retail \& Distribution Management, 43(12): 1182-1202.

Qazzafi, S. (2020). Factor Affecting Consumer Buying Behavior: A Conceptual Study. International Journal for Scientific Research \& Development, 8(2): 1205-1208.

Ramya, N., ve Ali, S. M. (2016). Factors Affecting Consumer Buying Behavior. International Journal of Applied Research, 2(10): 76-80.

Ratcliffe, E., Baxter, W. L. ve Martin, N. (2019). Consumption Rituals Relating to Food and Drink: A Review and Research Agenda. Appetite, 134: 86-93.

Rook, D. W. (1985). The Ritual Dimension of Consumer Behavior. Journal of Consumer Research, 12(3): 251-264.

Sandıkçı, Ö. ve Omeraki, S. (2007). Globalization and Rituals: Does Ramadan Turn Into Christmas?. Advances in Consumer Research, 34: 610-615.

Schewe, C.D. (1973). Selected Social Psychological Models for Analyzing Buyers, Journal of Marketing, 37(3): 31-39.

Schwartz, S. H. (2009). Culture Matters. Wyer, R., et al. Understanding Culture, 127-50.

Sharifi, S. S. ve Esfidani, M. R. (2014). The Impacts of Relationship Marketing on Cognitive Dissonance, Satisfaction, and Loyalty. International Journal of Retail \& Distribution Management, 42(6): 553-575.

Sığrı, Ü. (2017). Gruplarda Bağlılık ve Performans İlişkisi Üzerine Nitel Bir Ça1ışma. Uluslararası İktisadi ve İdari İncelemeler Dergisi, 16: 481-490.

Siğrı, Ü. (2018). Nitel Araştırma Yöntemleri. İstanbul: Beta Yayıncılık.

Simon, L., Greenberg, J. ve Brehm, J. (1995). Trivialization: The Forgotten Mode of Dissonance Reduction. Journal of Personality and Social Psychology, 68(2): 247-260.

Simpson, L., Taylor, L., O’Rourke, K. ve Shaw, K. (2011). An Analysis of Consumer Behavior on Black Friday. American International Journal of Contemporary Research, 1(1): 1-5.

Stanley, D. J., Meyer, J. P. ve Topolnytsky, L. (2005). Employee Cynicism and Resistance to Organizational Change. Journal of Business and Psycho$\log$, 19(4): 429-459.

Suri, H. (2011). Purposeful Sampling in Qualitative Research Synthesis. Qualitative Research Journal. 
Swilley, E. ve Goldsmith, R. E. (2013). Black Friday and Cyber Monday: Understanding Consumer Intentions on Two Major Shopping Days. Journal of Retailing and Consumer Services, 20(1): 43-50.

Şahin, E. ve Yünaçt, M. (2018). Küresel Tüketim Ritüeli «Kara Cuma»ya (Black Friday) Tüketici Tepkileri ve Çelişkili Satın Alma Davranışı. International Journal of Social Science, 71:387-404.

Taylor, S. E., Peplau, L. A. ve Sears, D. O. (2006). Social Psychology. Upper Saddle River, NJ: Prentice Hall.

Tek, Ö. B. (1999). Pazarlama İlkeleri: Global Yönetimsel Yaklaşım, Türkiye Uygulamaları. 8. Baskı, Beta Basım Yayım Dağıtım, İstanbul.

Tetreault, M. A. S. ve Kleine III, R. E. (1990). Ritual, Ritualized Behavior, and Habit: Refinements and Extensions of the Consumption Ritual Construct. Advances in Consumer Research, 17: 31-38.

Thietart, R. A. (2001). Doing Management Research: A Comprehensive Guide. Sage.

Thomas, J. B. ve Peters, C. (2011). An Exploratory Investigation of Black Friday Consumption Rituals. International Journal of Retail \& Distribution Management, 39(7): 522-537.

Tokgöz, E. (2020). Tüketicinin Kin Tutma Eğiliminin Pazardan Geri Çekilme Niyeti Üzerinde Etkisi: Tüketici Sinizminin Aracı ve Düzenleyici Rolü. Yönetim ve Ekonomi Araştırmaları Dergisi, 18(1): 36-58.

Triandis, H. C. (1996). The Psychological Measurement of Cultural Syndromes. American Psychologist, 51(4): 407-415.

Wamwara-Mbugua, L. W. (2008). Situational Ethnicity and Gift Giving Behavior Among Immigrant Mothers. Journal of International Management, 126.

Werbner, P. (1986). The Virgin and the Clown Ritual Elaboration in Pakistani Migrants' Weddings. Man, 21(2): 227-250.

Wright, D. E. ve Snow, R. E. (1980). Consumption as Ritual in the High Technology Society. Rituals and Ceremonies in Popular Culture, 338.

Witt, U. (2010). Symbolic Consumption and the Social Construction of Product Characteristics. Structural Change and Economic Dynamics, 21: 17-25.

Yau, O. H., Chan, T. S. ve Lau, K. F. (1999). Influence of Chinese Cultural Values on Consumer Behavior: A Proposed Model of Gift-Purchasing Behavior in Hong Kong. Journal of International Consumer Marketing, 11(1): 97-116.

Yetmez, İ. (2020). Kadın Tüketicilerin Black Friday Kampanyasına Yönelik Alg1larının İncelenmesi. Yönetim, Liderlik ve Pazarlama, 3. 
Yağar, F. ve Dökme, S. (2018). Niteliksel Araştırmaların Planlanması: Araştırma Soruları, Örneklem Seçimi, Geçerlik ve Güvenirlik. Gazi Sağllk Bilimleri Dergisi, 3(3): 1-9.

Yıldırım, A. ve Şimşek, H. (2008). Nitel Araştırma Yöntemleri. (6.Baskı). Ankara: Seçkin Yayıncılık

Zarantonello, L. ve Luomala, H. T. (2011). Dear Mr Chocolate: Constructing a Typology of Contextualized Chocolate Consumption Experiences Through Qualitative Diary Research. Qualitative Market Research: An International Journal, 14(1): 55-82. 


\title{
THE RELATIONSHIP BETWEEN TRANSFERRED RITUAL WITH CONSUMER ATTITUDE AND PURCHASING BEHAVIORS: THE CASE OF BLACK FRIDAY
}

\author{
EXTENDED ABSTRACT
}

\section{Introduction}

Rituals, a kind of expressive, symbolic activity (Rook, 1985) consisting of multiple behaviors that tend to be repeated over time, and celebrated worldwide with the effect of globalization, are transferred from different geographies. For example, Christmas has become one of the rituals celebrated annually worldwide, even in countries without a Christian tradition (McKechnie and Tynan, 2006). Similarly, wedding rituals involve a mixture of local and Western styles under the influence of globalization (Befu, 1984). On the other hand, although the ritual transfer from the West to the East is carried out together with the rituals in the East, it is not easy to adopt the rituals transferred from the West due to the deep connection of the rituals to the culture they belong to. Especially transferred rituals have been examined in terms of their effects on marketing habits. However, no one study that examined the relationships of a transferred ritual with consumer attitude and buying behaviors was confronted before. Thus, we will analyze in this study this issue with reference to cognitive dissonance theory and cynicism.

On the other hand, it is thought that the research findings will be useful for practitioners to create marketing strategies. It is considered that addressing the subject with relevant theories and approaches within the framework of consumer attitudes and behaviors, cognitive dissonance theory and consumer cynicism will make the research unique by contributing to the analysis of the relationship between the consumer attitude, buying behavior, the culture that consumer interacts with and the transferred ritual.

\section{Theoretical Framework}

Gregory, Munch and Peterson (2002) state that culture is linked to values and beliefs, ideas and attitudes, and symbols and objects used as communication methods. Ritual, a historical phenomenon, is nourished by the social conditions, belief systems and cultural structure that constitute it. For example, in a study conducted on individuals who immigrated to America from countries such as Thailand, India and Kenya, it is stated that some immigrant mothers are worried that something will happen to the baby if they give or receive a gift before birth. Therefore they are against the "Baby Shower" ritual. However, some immigrant mothers perform this ritual even if it is not included in their own culture (Wamwara-Mbugua, 2008). In this context, "ritual has an extremely powerful effect on behavior", 
which is closely related to the values adopted by the individual (Tetreault and Kleine, 1990).

There are many studies in the literature that deal with the relationship between rituals and buying behavior. (Kazançoğlu and Aytekin, 2014; Ratcliffe, Baxter and Martin, 2019; Rook, 1985; Sandıkçı and Omeraki, 2007). As one of the novel rituals that are transferred from the West, Black Friday arouses curiosity among researchers. Since 2012, Black Friday, held on the last Friday of November, has become a consumption ritual in Turkey. In addition, purchasing rates of consumers are high on Black Friday (Akcan, Gençyürek Erdoğan and Karaçor, 2020; Kılıç, Budak and Kılıç, 2020; Onbaş, 2020). It has been observed that intense criticism was made especially on social media, regarding an event that is expected to be positive in terms of consumer interest (Çetinkaya and Ceng, 2018). In fact, Black Friday is criticized by some consumers in the context of Islamic values and capitalism (Dağtaş and Yıldırım, 2018). Despite the high consumption rates in the Black Friday ritual, consumers' negative attitudes create a contradiction.

In various studies, the relationship between the transferred ritual and culture (Langer, Lüddeckens, Radde and Snoek, 2006; Langer, 2011; Werbner, 1986), the relationship between rituals and buying behavior (Kazançoğlu and Aytekin, 2014; Ratcliffe et al., 2019; Rook, 1985; Sandıkç1 and Omeraki, 2007), consumer cynicism (Atılgan, İnce and Yılmaz, 2017; Bozoklu and Ermeç, 2020; Güven, 2016; Özkaya and Ülker, 2020; Tokgöz, 2020), consumer cynicism towards the name of "Black Friday" and its reflections on the media (Akcan et al., 2020; Çetinkaya and Ceng, 2018; Dağtaş and Yıldırım, 2018; Yetmez, 2020), campaign analysis on Black Friday (Onbaş, 2020), the contradiction between consumers' attitudes towards Black Friday and their buying behaviors (Şahin and Yünaçtı, 2018) were examined. Within the scope of the literature review, no study has been found that reveals the reasons for the cynical attitudes of consumers engaged in buying behavior regarding a ritual transferred from the West, the relationship of these attitudes with culture and the justifications underlying the buying behavior of consumers within the framework of the cognitive dissonance theory.

\section{Methodology}

In this study, an interview was conducted in order to reveal the relationships of Black Friday as a ritual with consumer attitude and buying behaviors. The opinions of the consumers were taken within the framework of semi-structured interview questions based on the literature on cognitive dissonance theory, cynicism, buying behavior and consumer attitude. The research was carried out on Black Friday on 27.11.2019 in Ankara.

In the research, the purposeful sampling method was used. Since consumer attitudes and buying behavior regarding the Black Friday ritual were examined, individuals who had a regular income and had shopping on Black Friday were 
preferred. In addition, the opinions of store and cargo employees were also included in the study.

Qualitative data were analyzed through the QDA Miner program and the frequency of the codes was revealed. Helm, Moulard and Richins (2015) developed a scale based on the literature on consumer cynicism and interviews with consumers. Scale encompasses all three elements of the concept of cynicism: general opportunism, particular opportunism that harms consumers, and deception. Based on the scale developed, related literature and the concepts obtained within the scope of the interview, the code and theme list related to cynicism was created. Regarding the cognitive dissonance theory, a code and theme list was created based on related literature, Festinger's (1957) article and consumer opinions.

The interviews continued until the participants started to repeat the same things on certain topics (Thietart, 2001), that is, until the saturation level was reached. Within the scope of the research, one-on-one interviews were conducted with 25 consumers, two store attendants and two cargo company employees.

\section{Results}

Within the scope of the interviews, it was seen that 16 out of 25 consumers show buying behavior despite having negative attitudes. The majority of consumers who have negative attitudes state that the adjective "black" has a negative connotation. Besides, they state that it evokes death, sadness and bad day. In this context, it is seen that there is a negative psychological attitude towards the name Black Friday. As a result of the interviews, the fact that the Friday, which is regarded as blessed by Muslims, is described as black leads to a negative attitude by consumers. Moreover, Black Friday is seen as belonging to Western culture and cannot be reconciled with Turkish culture. In this context, it is seen that consumers have a negative attitude in terms of culture. Furthermore, Black Friday is referred to as "consumption frenzy" and "part of the capitalist system". Therefore, consumers negatively interpret Black Friday with the concepts of capitalism and overconsumption.

The obtained findings also display that 18 consumers have mistrust and fear of being deceived regarding the companies organizing Black Friday. From the statements of the store employees, it was concluded that consumer demand and product returns were high in Black Friday shopping.

\section{Conclusion}

In the light of the research, it has been observed that consumers have a negative attitude about the Black Friday ritual transferred from the West, mostly due to psychological, religious and cultural reasons, as well as thoughts about capitalism and excessive consumption, and they share a negative approach to the Black Friday phenomenon and its name. In addition, it was concluded that there is a clear con- 
tradiction between the attitudes of the consumers and their buying behavior. It was observed that consumers try to rationalize their buying behaviors by basing them on various reasons. Moreover, it was concluded that some consumers performed impulsive buying behavior on Black Friday. 


\section{Ek-1 MÜLAKAT SORULARI}

Değerli Katılımc1,

Yapacağımız bu mülakat ile Kara Cuma indirimlerinin tüketici tutumu ve satın alma davranışı üzerine etkisi araştırılacaktır. Vereceğiniz cevapların doğru veya yanlış sonuçları yoktur. Önemli olan kendi bakış açınız doğrultusunda doğru olduğuna inandığınız görüşlerinizi samimi bir şekilde paylaşmanızdır. Sorulara vereceğiniz cevaplar tamamen gizli tutulacak ve üçüncü şahıslarla bilgi paylaşımı yapılmayacaktır.

\section{Demografik Bilgiler}

- Eğitim:

- Cinsiyet:

- Meslek:

- Medeni Durum:

- Yaș:

- Gelir Düzeyi: Yıllık ortalama geliriniz ne kadar?

\section{Tüketici Tutumu ve Sinizm}

- Kara Cuma'ya ilişkin ne düşünüyorsunuz? Sizin için neyi ifade ediyor? Neden? (Sinizm)

- Kara Cuma isminin kullanılması hakkında ne düşünüyorsunuz? Neden? (Sinizm)

- Sizce toplumun Kara Cuma ismine ilişkin görüşü nedir? Bu görüşü önemsiyor musunuz? (Sinizm)

- Kara Cuma’ya ilişkin görüşlerinizi çevrenizle ve/veya sosyal medyada paylaşıyor musunuz? (Sinizm)

- Artık firmalar tarafindan bu günün ismi değiştiriliyor? Efsane Cuma, Muhteşem Cuma gibi isimler türetiliyor. Bu konu hakkında ne düşünüyorsunuz?

- Siz firmaların yerinde olsaydınız Kara Cuma ismiyle mi indirim kampanyası yapardınız? Ne zaman bu indirimi düzenlerdiniz?

- O gün alışveriş yaparken neler hissediyorsunuz? Stokların sınırlı olması, birçok insanın alışveriş yapıyor olması sizi nasıl hissettiriyor? 
- Kara Cuma günü öncesi yapacak olduğunuz alışverişinize ilişkin bir planınız/stratejiniz oluyor mu? Örneğin:

$>$ İndirimleri takip etmek

$>$ Nerede alışveriş yapılacağına karar vermek

$>$ Mağazaları haritalandırmak

$>$ Mağaza içi eylem planları geliştirmek

- Her sene Kara Cuma'da alışveriş yapıyor musunuz?

- Kara Cuma alışverişini günün hangi saati yapıyorsunuz?

\section{Satın Alma Davranışı}

- Neden Kara Cuma günü alışveriş yapıyorsunuz?

- Kara Cuma günü harcamanız veya aldığınız ürün miktarı diğer günlere kıyasla fark ediyor mu?

- O gün aklınızda olmayan şeyleri de aldığınız oluyor mu?

- Nereden alışveriş yapmayı tercih ediyorsunuz? (İnternet, AVM, AVM d1şındaki mağazalar)

- Bu alışveriş genel olarak beklentinizi karşılıyor mu? (Sinizm) 